\title{
Incentives and Ratcheting in a Multiproduct Firm: A Field Experiment
}

\author{
Francisco Brahm \\ Judge Business School, University of Cambridge \\ Joaquin Poblete ${ }^{1}$ \\ School of Management, Pontificia Universidad Católica de Chile
}

\begin{abstract}
We develop a model and derive behavioral predictions for a multiproduct sales force subject to goals set based on past performance. We test these predictions using a field experiment in which 53 salespersons from a Chilean beverage company face exogenous variation in monthly sales goals. Confirming our predictions we found that 1) Absent strategic considerations - no goal ratcheting-, salespersons increase (decrease) sales in the product category for which the return to effort increases (decreases), 2) Including strategic considerations behavior reverses: salespersons that expect high goal ratcheting decrease (increase) sales in the category for which the return to effort increases (decreases), 3) Sales did not change for the average salespersons, reflecting heterogeneity in the expectations of goal ratcheting rather than unresponsiveness to incentives. Our study points at the importance of the dynamics of incentive design, in particular, the importance of understanding the dynamics of goal setting in firms.
\end{abstract}

Keywords: Incentives, Strategic behavior, Ratchet effect, Field experiment.

\section{Introduction}

How people respond to monetary incentives is a fundamental question for management scholars and practitioners. When workers evaluate an action in the presence of incentives, two considerations are taken into account. The first (and most straightforward) consideration is a trade-off between the reward and the private cost of the action, given the current incentive structure. We call this the "direct effect". The second (and less straightforward) consideration is strategic. It considers how the action might induce the principal to change the incentive scheme in the future (e.g., the incentive slope). We call this dynamic consideration the "strategic effect".

Most of the theoretical and empirical literature on formal incentives focus on designing effective "oneshot" incentive systems rather than studying the best way to update the system over time (see Gibbons and

\footnotetext{
${ }^{1}$ Funding: Poblete acknowledges research support from ISCI Institute (CONICYT FB0816), the Institute for Research in Market Imperfections and Public Policy, (ICM IS130002) and FONDECYT grant No. 11140525
} 
Roberts, 2013 and Lazear and Oyer, 2013 for reviews) $)^{2}$. Consequently, the relative importance and the inner workings of strategic effects are less understood. From an empirical perspective, understanding the dynamics of incentive design in managerially relevant settings remains a pending issue.

The importance of understanding both effects has been particularly clear in the literature that study incentive ratcheting, which includes ethnographic accounts (Roy, 1952), theoretical models (Gibbons, 1987; Weitzman, 1980), lab experiments (Charness et al, 2011) and evidence from administrative data (Indjejikian et al 2014). Incentive ratcheting can be defined as the practice of setting next period goals, piece rates or any other key incentive parameter based on current-period performance. Incentive ratcheting is an important type of ex-post adjustment to incentive schemes that may induce a-priori strategic reactions from workers. The strategic reaction to incentives due to ratcheting is clearly explained by a worker quoted in Mathewson (1931): "I have learned through sad experience that the more your superiors find they can get out of you the more they come to expect. The only way to protect yourself is never to work at anything like full capacity. I know that most restriction is due to the worker's desire to save and protect herself and not to any other motive.” (p. 65). Although field evidence has convincingly documented that goals tend to increase with past performance (Indjejikian et al 2014; Anderson et al, 2010), evidence of output restriction from the field is scarce and mainly correlational (Bol and Gil, 2015; Anderson et al, 2010; Bouwens and Kroos, 2011). Causal evidence comes from lab experiments (Charness et. al., 2011; Cooper et al, 1999) with the exception of Bellemare and Shearer (2014) which, by means of a field experiment with treeplanting workers, provide evidence of significant output restriction.

By focusing on the direct and strategic effects in a ratcheting context, we confront two issues that has limited extant research. First, it is difficult to disentangle empirically the direct from the strategic effect. This is so because the exercise requires exogenous variation both in incentive payments and in worker's beliefs regarding the ratcheting behavior of their supervisors. To the best of our knowledge, the only study providing exogenous variation on both dimensions is Cooper (1999). Using lab experiments with Chinese

\footnotetext{
${ }^{2}$ In making this claim we do not consider informal incentives, or "Relational contracts", which by their non-enforceability nature are related to the dynamics of repeated interactions between principal and agent.
} 
managers, they show that in response to incentives, agents increased effort (i.e., the direct effect); however, when incentive ratcheting kicked in, output was restricted gradually, and this decrease was much faster when the beliefs of a stronger ratcheting behavior was primed by researchers (i.e., the strategic effect). In our study we provide, to our knowledge, the first field evidence on the relative magnitude of the direct and strategic effects. ${ }^{3}$

Second, we extend research on goal setting by analyzing its interaction with pay for performance. Although wage-irrelevant goals have been already studied in psychology and economics (e.g., Locke and Latham, 2002; Abeler et al, 2011; Corgnet et al, 2015), the interaction between wage-relevant goals and monetary incentives hasn't been studied in extant research, even though wage-relevant goals arguably tends to be the rule rather than the exception. This is particularly true in sales force management: Sinha and Zoltners (2001) and Zoltners et al (2006) show that $82 \%$ of sales forces have goal-based incentives schemes. We contribute to this literature by showing that a key interaction is the consideration of how wage-relevant goal are updated over time, and how this can generate strategic responses from salespersons.

The context of our study is a multiproduct salesforce in a large Chilean beverages company that is subject to goal ratcheting. In order to understand the problem, we first tailor a model to our setting and then derive precise predictions for the behavior of salespersons. In the model, salespersons sell more than one product, for example wine and spirits, and are paid according to the sales to goal ratio for each product. The model predicts that if an agent is not expecting any goal ratcheting (i.e., the extent to which future goals reflects current performance) or is simply a myopic maximizer, an unexpected decrease (increase) in the goal of wine relative to spirits should increase (decrease) the ratio of sales of wines relative to spirits. This is the direct effect at play: the sales effort are directed to the category with higher benefit-to-cost ratio, that is, the one with a lower goal.

On the other hand, if the agent expects ratcheting, she is unwilling to increase sales of wine relative to spirits because she anticipates a punishment via future increases in goals. Moreover, if ratcheting is high

\footnotetext{
${ }^{3}$ Bellemare and Shearer (2014) identified the "strategic effect" by manipulating how the piece rate is updated; they do not observe the baseline "direct effect" of a piece rate versus a fixed wage.
} 
enough, salespersons will simply comply with the goals imposed by their supervisors, that is, an unexpected decrease (increase) in the goal of wine relative to spirits should decrease (increase) the ratio of sales of wines relative to spirits. We study relative sales and goals (i.e., ratios) because this allows us to avoid income effects in the analysis. By comparing the sales reaction to goals when the agent expects to be subject to ratcheting (aggregated effect of incentives) with the reaction they would have if they don't expect goal ratcheting in the future (only a direct effect of incentives), we can separate the direct and strategic responses to goal ratcheting.

To experimentally test our predictions within the company, we analyze the behavior of 53 salespersons in four cities. We studied historical records of sales and goals for 25 months, and then we helped the firm to design a field experiment for two consecutive months. In this experiment, an exogenous variation of plus and minus $15 \%$ in the goals of the two product categories was introduced. To include expectations about ratcheting in our experiment, we measured, using the historical data, the extent to which the salespersons supervisors adjusted the goals in relation to prior performance. To make sure our identification is valid we show that the matching process between salespersons and supervisors is largely exogenous.

The experimental variation in goal levels, plus the plausible exogeneity in ratcheting expectations, allow us to identify the causal impact of goal ratcheting and to disentangle the direct from the strategic effects. The main contribution of this paper, is that we are the first to provide this type of evidence in a real world context.

Our results yield several insights. First, salespersons show no reaction to a change in incentives on average. The ratio of sales between spirits and wine did not change with the exogenous change in the goal ratio. This is consistent with recent literature that shows that in many settings monetary incentives may not be useful (Gneezy et al, 2011). Nonetheless, if we separate the direct and strategic effects, we find that this is not because unresponsiveness to monetary incentives but rather, because the direct and strategic effects move in opposite directions and cancel each other.

Second, there is important variation of salesperson behavior with respect to the ratcheting behavior of supervisors. If supervisors do not have a history of goal ratcheting, salespersons behave in a way consistent 
with the direct effect: facing a decrease in the wine to spirits goal ratio, salespersons increased the sales of wine relative to spirits. However, if ratcheting is strong, the results reverse themselves. Facing the same exogenous decrease in the ratio of wine to spirit goals, these salespersons presented a decrease in the ratio of wine to spirit sales. The difference between these two results indicates that, when ratcheting is strong, the strategic effect of salespersons outweighs the direct incentive effect.

Third, this behavior varies notably with worker tenure. During their first year in the company, workers behave in a way consistent with ignoring (or not understanding) goal ratcheting. As salespersons tenure increase, salespersons behavior incorporates more of the strategic effect and moves away from the myopic maximizing behavior shown in early periods.

Our results contribute to the understanding of goal setting, by showing that not only the interaction between goals and monetary rewards are important (via the direct effect), but that the nature of this interaction depends on the agent's expectation regarding the dynamics of goal setting (the strategic effect). In the case of the multiproduct firm we study, the behavior of salespersons in terms of goal compliance varied dramatically depending on the expectation of goal ratcheting from their supervisors. Our paper suggests that managers should consider not only the design of the incentive system but also how the parameters like goals are updated over time.

More generally, our results suggest that studying strategic effects in more detail would improve our understanding of formal incentives. Much work has considered incentives structures and other rules of the game as exogenous. Here we relax this assumption and allow that behavior may change the rules. This generates at least to two broad implications. First, the same incentives structure in different strategic contexts may have very different effects on the behavior of agents. Second, by not distinguishing and measuring the strategic effect, we might miss-interpret empirical results. For example, studies finding strong short impact of incentives (e.g., Shearer, 2004) might fail to capture the strategic effects arising from longer time spans, when expectations get updated and strategic behavior kicks in (Obloj and Sengul, 2012). Further, many behavioral results might be wrongly interpreted as irrational behavior or non-responsiveness 
to incentives, while in fact subjects may be simply acting strategically; similarly, a "true" behavioral response might get reverted over time because of expectations updating (Jayaraman et al, 2015).

The rest of the paper is organized as follows. Since our theoretical model is tailored to our setting, in the second section we introduce institutional details. In the third section we present our theoretical model and our predictions. In the fourth section we detail our experimental design, and in the fifth we present our empirical analysis. In the sixth section we discuss the results and conclude.

\section{Institutional details}

We collaborated with "Compañía Cervecerías Unidas" (CCU), a large Chilean beverage provider. Until 1993, CCU focused solely on the beer business and was at that time the largest brewery in Chile with an 80\% historical market share. During the last two decades, however, CCU diversified intensively. In 1994, CCU acquired "Viña San Pedro" to become the second largest wine producer in Chile, and through its subsidiary "ECUSA", entered the soft drink business (carbonated drinks, concentrates, and juices). The soft drink portfolio was completed by the formation of a joint-venture with Nestlé in 2007. Today, ECUSA is the second largest soft drink producer in Chile. Furthermore, in 2003 CCU diversified into the spirits business through its subsidiary "Compañía Pisquera de Chile" and became the largest producer and distributors of spirits. In each of these product categories, CCU produces its own brands, as well as licensed and imported brands, maintaining licensing agreements and joint ventures with international firms such as Heineken and Pepsico. During 2013, CCU had the following sales breakdown within Chilean territory across four product categories (percentage of the liter volume in parentheses): $41 \%$ in soft drinks (60\%), $42 \%$ in beer $(34 \%), 9 \%$ in wine $(2 \%)$, and $8 \%$ in spirits $(2 \%) .{ }^{4}$

In large urban areas, each product division has its own regional sales force. These large urban regions account for approximately $60 \%$ of total volume. In contrast, in the rest of the country the sales function was centralized in 2005 to the service division "Comercial CCU" (C.CCU). In smaller regions, C.CCU provides

\footnotetext{
${ }^{4}$ There is a fifth and significantly smaller category, confectionary, that represents less than $3 \%$ of sales and that is measured in kilograms. As opposed to the other categories only some customers buy confectionary. This fifth smaller category is largely irrelevant in our analysis.
} 
"sales services" to the four product divisions by having a sales force that sells the complete portfolio of CCU products.

\subsection{Organization, incentives and the goal setting process at C.CCU}

C.CCU determines its sales force strategy independently (i.e., sales force size, incentive scheme, goal setting process, and sales territory definitions) but coordinates marketing across each product divisions (i.e., sales promotions, new product releases, and pricing). Each month, C.CCU charges a transfer price to each division for its services.

C.CCU is organized geographically: there is a sales director for the north zone of Chile and a sales director for the south zone. These two directors report to the central office and CEO of C.CCU which is located at the headquarters of $\mathrm{CCU}$, in the capital of Chile. The north zone is divided into five geographical regions and the south zone is divided into ten regions. The regions are managed by a set of seven regional sales managers, three of which operate in the north zone and four in the south zone. Thus, each regional manager manages approximately two regions. The next organizational layer is comprised of sales supervisors. There are a total of 36 sales supervisors, approximately five per regional manager. Sales supervisors directly supervise the salespersons. Given that there are approximately 230 salespersons, each sales supervisor has direct supervision of six to seven salespersons. Each salesman works six days a week in a specific and exclusive territory. In a typical day, a salesman spends one hour at the C.CCU offices to coordinate with the sales supervisor and other areas of the company (marketing, logistics, etc.), and then spends six to seven hours on the road, visiting clients. On average a salesman visits 30 clients per day, and commuting time between clients accounts for about $30 \%$ to $40 \%$ of their time.

On average, 55\% of the monthly wage of the sales force is a monetary incentive based on sales goal attainment. The rest is a fixed wage (35\%) and a variable payment base on task execution such as client coverage and service level (10\%). Regional salespersons are given a sales goal at the start of each month within each product category. The monetary incentive that the salespersons receives at the end of the month

is determined by the following formula: Payout $=f\left(\sum_{i=1}^{4}\left[\theta_{i} \times \frac{S A L E S_{i}}{G O A L_{i}}\right]\right)$, where "i" is product category 
and $\theta_{i}$, is the weight of each product category (which in our data is fixed over time). The payout function "f()" is a linear increasing function that starts paying at $75 \%$ (of the goal) and is capped at $125 \%$. The regional sales manager and sales supervisors are paid using the same structure as the salespersons.

The monthly goal-setting process works in the following way. At the start of each month the headquarter of C.CCU sets sales goals for each of the 15 regions in each of the four product categories which are then communicated to each regional sales manager. This process attempts to predict changes in demand and often incorporates qualitative information, for example, by including the assessment of the sales director of the two zones of the country (north and south). Once in the hands of the regional managers, the goals are rarely changed (only in cases of force-majeure). Regional sales managers, however, have latitude in how they set the goals of each supervisor, whom in turn have latitude in how they structure the goals of the salespersons under their supervision. The goal setting process has only two active restrictions for regional managers and supervisors. First, the goals must be congruent between levels of the company, that is, the sum of the goals of salespersons in a specific product category must be equal to the supervisor goal in that category ${ }^{5}$; the same applies between the regional manager and the sales supervisor. Second, all the goals must be reported back to the central office within the first 5 working days of the month.

\subsection{Regional units under study}

We selected four regions for the field experiment (explained in section 4): two regions in the south zone of C.CCU, "Valdivia" and "Temuco", managed by the same regional sales manager, and two regions in the north zone, "Antofagasta" and "Calama", again managed by the same regional sales manager (but distinct from the regional manager at Valdivia and Temuco). This selection was executed jointly with the company balancing two objectives: i) to maximize the representativeness of the sample, ii) to allow for sufficient experimental power ${ }^{6}$. In Valdivia there are six salespersons and two sales supervisors; in Temuco there are

\footnotetext{
${ }^{5}$ For example, the sum of the salespersons' goals for wine that the supervisor defined has to be equal to the wine goal that the regional manager defined for that particular supervisor. The same applies for the rest of the categories.

6 This sample secured sufficient power for our experiment. Using the recommendation of List et al (2011), namely a significance level of $5 \%$ and a power level of $80 \%$, with this sample we can detect approximately an aggregate $6.4 \%$ change or more in our variable of interest. This represents $64 \%$ of its standard deviation. As explained below, the variable of interest is the ratio of sales
} 
20 salespersons and three sales supervisors; in Antofagasta there are 19 salespersons and three sales supervisors; and in Calama there are eight salespersons and one sales supervisor. In total, we observed 53 salespersons and nine supervisors ${ }^{7}$.

\section{Model and Predictions}

The model is specific to the institutional details of CCU explained above. Let $s_{i}$ be the sales of product $i$ and $g_{i}$ be the goal for that product, then payment to the agent is an increasing function $f$ of the weighted sum of the compliance ratios $s_{i} / g_{i, \text { where }} \theta_{i}$ is the weight of product $i$.

For simplicity, we assume the agent's cost is quadratic $c(\vec{S}(t))=\beta \sum_{i=1}^{4} \frac{1}{2} s(i, t)^{2}$, where $\beta$ is simply a parameter that affects the marginal cost of effort. ${ }^{8}$ Agents discount the future using discount factor $\delta$.

A rational agent chooses sales in each category, each period to solve:

$$
\max _{S(i, t)} \sum_{t=1}^{2} \delta^{t-1}\left(U\left[f\left(\sum_{i=1}^{I}\left[\theta_{i} \times \frac{s(i, t)}{g(i, t)}\right]\right)\right]-c(\vec{S}(t))\right)
$$

Where $\mathrm{U}$ is a concave utility function, $\delta$ is a discount factor and $\mathrm{f}()$ is the compensation payment described in the previous section. We assume first order conditions are sufficient to characterize the agent's optimal actions $\mathrm{s}(\mathrm{i}, \mathrm{t})^{9}$. For simplicity the model has only 2 periods.

We first consider the case when the agent does not expect future goals (period 2 goals) to change with current performance. This is the appropriate assumption if there is no ratcheting. The first order conditions in the agent's maximization problem are given, for every $i$ and $t$, by

of wine to sales of spirits. Thus, a $6.4 \%$ change is equivalent to an increase in $3.5 \%$ in the sales of one category and decrease of $3.5 \%$ in the sales of the other category. Since we created exogenous variance of $+-15 \%$ in the goals of the categories, to detect a +3.5 percent change in sales is likely with a sample of 53 .

${ }^{7}$ We excluded 8 salespersons devoted exclusively to the supermarket channel. These salespersons are very different from the rest of the sales force and were deemed not suitable for our study: Supermarkets place purchase orders independently -without input from the salespersons- and consequently, these salespersons have much lower latitude in deciding which product to "push" into the market. In addition, these salespersons report to a set of different sales supervisors than the rest of salespersons.

${ }^{8}$ The quadratic assumption is not necessary to obtain the results but greatly simplifies the exposition. A sufficient assumption for our results to hold is that the ratio of marginal costs need to be a decreasing function of the ratio of sales (this is similar to assuming homothetic preferences). This more general assumption is compatible with non-separable, asymmetric cost functions, and allows for the marginal cost of effort on one activity to be increasing, decreasing or constant on the other activities.

${ }^{9}$ The function "f()" maps goal attainment to payment and is linear increasing with a minimum of $75 \%$ and a cap of $125 \%$. Thus, the function is only concave beyond $75 \%$; below this value, it is convex. In theory this might constitute a problem. However, in practice in the 25 months prior to the experiment $97 \%$ of the time compliance was above $75 \%$, the concave part of the payment function. Also, there are no observations of compliance close to zero, indicating that corner solutions can be ruled out. 


$$
U^{\prime}\left[f\left(\sum_{i=1}^{I}\left[\theta_{i} \times \frac{s(i, t)}{g(i, t)}\right]\right)\right] \times f^{\prime}\left(\sum_{i=1}^{I}\left[\theta_{i} \times \frac{s(i, t)}{g(i, t)}\right]\right) \times \frac{\theta_{i}}{g(i, t)}=\beta s(i, t)
$$

It is easy to check that the effect of a change of the goal $g(i, t)$ on the sales of the product $s(i, t)$ is ambiguous because there is an income effect that goes on the opposite direction of the more intuitive substitution effect. Mathematically, while the third factor in the multiplication above unambiguously decreases with increases in $\mathrm{g}(\mathrm{i}, \mathrm{t})$, the first factor (the agent's marginal utility) increases with increments in $\mathrm{g}(\mathrm{i}, \mathrm{t})$ because of the concavity of the utility function. Although it is likely that for most goods, the effect of $\frac{\theta_{i}}{g(i, t)}$ will be larger than the effect of $U^{\prime}[$.$] , we cannot rule out the possibility of an ambiguous result. Thus,$ the overall effect on $s(i, t)$ of an increase in $g(i, t)$ is ambiguous.

However, dividing the first order condition for products $i$ and $j$ yields:

$$
\frac{s(i, t)}{s(j, t)}=\frac{g(j, t)}{g(i, t)} \frac{\theta_{i}}{\theta_{j}}
$$

From equation (3) the sensitivity of the ratio of sales to the ratio of goals is negative and equal to minus the ratio of weights of the payoff function. Given this result, we can unambiguously predict that the ratio of sales of products $i$ and $j$ depend negatively on the ratio of goals of products $i$ and $j .{ }^{10}$

Prediction \#1: If future goals do not depend on current sales, the ratio of sales for two products depends negatively on the ratio of goals for the same products.

We now add strategic interaction to the model in the form of ratcheting. In order to do this we assume that supervisors tend to increase future goals when today's sales exceed goals. In particular we introduce a parameter $\rho$, which indicates how future goals are affected when sales exceed goals. If $\rho=1$ then sales exceeding the goal in $10 \%$ means a $10 \%$ increase in the next period goal, while $\rho=0$ implies that current sales do not affect future goals. This, the parameter $\rho$ captures the extent of goal ratcheting in the goal updating process.

\footnotetext{
${ }^{10}$ If the two activities differ in terms of risk, then there might be important income effects that are not accounted for in this deterministic model. However, in our case the risk involved in wines and spirits (the two categories used in the experiment) are very similar. The average coefficient of variation of sales for wine and spirits are 0.406 and 0.430 , respectively.
} 
Ratcheting may be efficient when supervisors seek to learn about the characteristics of salespersons, demand or salespersons customers. In this simple model we simply take the ratcheting behavior of supervisors as given and try to infer its consequences on salespersons behavior. By including the ratchet effect in the model above, we obtain the following prediction. (See the appendix for a formal analysis and a numerical example that confirms this prediction).

Prediction \# 2: When future goals depend positively on current sales (in the presence of a positive ratchet effect $\rho$ ), the negative relationship between the sales ratio and the goals ratio becomes less negative. When the ratchet effect is strong (at sufficiently large levels of $\rho$ ), the relation may become positive.

To understand the logic behind this result consider a salesperson that is in a situation where she normally achieves $100 \%$ compliance with the goals. Foreshadowing our experiment, suppose that the goal for wines increase and the goal for spirits decrease. The direct response is to increase sales of spirits and decrease sales of wine (as explained in prediction 1). However if this salesperson expects ratcheting, this effect is reduced for two reasons:

a) Increasing sales of spirits is now costly because it will trigger an increase in future goals of spirits, reducing incentives to increase sales of spirits.

b) Because the sales of spirits does not increase as much as in the case without ratcheting (because of point a)), the income of the agent in the first period is reduced. This changes the incentives in the other category: Reducing sales of wine (as a result of an increased goal) becomes less attractive because the marginal utility of income has now increased. This reduces the incentives to decrease wine sales as compared to the case without ratchet.

Effects a) and b), contribute to decrease the negative relation between the ratio of goals and the ratio of sales.

To understand how the negative relationship may become positive, consider a salesperson that is subject to extreme ratcheting and therefore will never exceed the goal to avoid goal increments in the future. As the goal of spirits decrease, this salesperson will need to decrease the sales of spirits to avoid exceeding the goal. Following the same logic as in point b) above, because his utility function is concave this will 
increase the marginal utility of income, increasing the return to sell wine. As a result, the ratio of sales wine/spirit might increase, reversing the negative relationship observed under no ratcheting.

Intuitively, when facing extreme ratcheting, the salesperson finds it optimal to follow the goal. ${ }^{11}$ Empirically, this second case translates into the observation of "complying" behavior: when goals increase (decrease), salespersons increase (decrease) their sales accordingly.

Of course, if goal ratcheting is zero, the strategic effect is null and prediction \#1 remains unaffected.

Our two predictions are summarized in figure 1. When the ratchet coefficient is zero, the relationship between the goals and sales ratio is negative. However, as this ratchet increases, then the slope becomes less negative, eventually becoming positive.

A nice feature of our setting within a multi-category salesforce is that it provides: a) a clean prediction for the direct effect by analyzing the relationship between the ratio of sales and the ratio of goals of two categories (something that cannot be done with agents/salespersons on a single task/category because of the income and the substitution effects that go on opposite directions) and b) a prediction for the strategic effect that goes on the opposite direction than the direct effect, and thus, we are able to observe this effect playing out as decreasing or even a reversal of the negative relationship between the ratios coming from the direct effect.

\section{[Insert figure 1 around here]}

\section{Experimental design}

To test our predictions, we assisted C.CCU on the planning and implementation of exogenous changes in goals for the wine and spirits category at the regional level for two consecutive months, August and September, of 2013. On the first day of the first month of the experiment, the C.CCU central office sent us their proposed goals for the wine and spirits categories. Before they were passed on to the regional managers, we randomly assigned an exogenous variation of plus or minus $15 \%$ of the original goal for each

\footnotetext{
${ }^{11}$ When there is ratchet effect, the absolute level of the goal is also relevant. If the goal is set at a level so high that is unreachable for the agent, then the effect of ratcheting disappears.
} 
region. Then, on the second day of the month, the senior manager at headquarters sent the new goals (which carried the exogenous "adjustment") to the regional sales manager as part of the regular goal setting process of C.CCU. This process yielded the following treatment assignment. During August, in the regions of Antofagasta and Calama we introduced a $15 \%$ increase in the goal for spirits and a $15 \%$ decrease in the goal for wine. In contrast, in the regions of Valdivia and Temuco, we generated a 15\% decrease in the goal of spirits and a $15 \%$ increase in the goal of wine. Given the random treatment assignment to each region, C.CCU could not introduce an a-priori expectation that might have biased the experiment. Through this experimental design, we created opportunities for salespersons to exploit the exogenous change for their own benefit: if there is no strategic response by salespersons, we predict an increase (decrease) in their sales in the category with a $15 \%$ goal decrease (increase). By contrast, if salespersons have a strong strategic response, for example, because of past-goal ratcheting behavior, the latter behavior may not be observed. Our predictions indicate that the negative relation between the ratios of goals and the ratio of sales may be increasingly muted, and even become positive, provided that the strategic response to expected ratcheting is strong enough.

Following the same procedure, for the month of September, the change in the goals was as follows: in the regions of Antofagasta and Calama we generated a $15 \%$ decrease in the goal of spirits and a $15 \%$ increase in the goal of wine; in contrast the regions of Valdivia and Temuco, we generated the opposite change, a $15 \%$ increase in the goal of spirits and a $15 \%$ decrease in the goal of wine. Thus, in September we reversed the changes implemented during August, generating within subject variance in the experimental treatment. This was done in agreement with C.CCU in order to have a neutral impact on the aggregate sales of C.CCU on the two months, both at the category or region level. In this way, C.CCU was completely blind to the experimental changes it would experience only in the first month and not in the second. To avoid contamination of the September goals, we kept the experiment and the changes we executed isolated to the staff of analysts of C.CCU that built the goals for the senior manager of C.CCU 
(with whom we worked). This senior manager was the responsible for the approval, revision and communication of the final goals to each regional sales manager ${ }^{12}$.

Goal changes at the regional level trickle down the firm's hierarchy through the delegated goal setting process at C.CCU. Thus, the exogenous $15 \%$ increase or decrease may not be transmitted homogeneously to the salespersons; instead, there may be heterogeneous transmission of the changes on the salespersons, some increasing $20 \%$ and other $10 \%$ (in relation to the counterfactual goal that "it would have received without the experiment"). This heterogeneous transmission might be endogenous, for example, to salespersons capability or its geographical area (its market). This could affect our estimates: if a supervisor executes a higher pass-through on salesperson that have a higher expected sales (i.e., "goals follow expected sales"), then an uncorrected estimation is potentially biased against the direct effect. For time invariant unobservables (e.g., stable salesperson characteristics), the inclusion of fixed effects mitigates this problem. However, time variant changes in a salesperson capability or its market cannot be corrected by fixed effects. We executed a robustness check where we show that our results remain unchanged when we take into account this time-variant endogeneity in the "pass-through" of the exogenous shock ${ }^{13}$.

A mitigating factor for the endogeneity of the "pass-through" is the restriction that goals have to add across layers, meaning that any heterogeneous assignment has to be compensated, maintaining $15 \%$ changes in the region as a whole. Thus, even though we can't guarantee homogeneity of changes across salespersons, on average we do create exogenous variance for the group of salespersons in a region. In other words, we created an instrumental variable at the region level.

\footnotetext{
12 To see if the period of treatment of September has an effect in our results we executed the following robustness check: we added to the vector $\mathrm{Z}$ of the equation (11) (see section 5 below) a dummy taking the value of 1 if the period corresponded to September. The results did not change, indicating that contamination from reversing the August treatment during September is not affecting our estimates.

${ }^{13}$ In this robustness check, we generated a prediction of the goals that the salespersons would have had without the experiment. This prediction was based on a model of goals as a function of previous sales, supervisor ratcheting, month (to capture cyclicality) and year estimated for the 25 months prior to the experiment. Then, we computed the ratio of this predicted goal to the actual goal for both wine and spirits categories in the two months of the experiment (we observed the actual goals that were generated for salespersons during the experiment). Then we added these ratios as control variables in the vector $Z$ of the equation (11) described in section 5.3 below. The results of our variables of interest did not change by adding these new covariates.
} 
Following the categorization from Harrison and List (2004), our experiment is a "natural field experiment" in which the subject pool did not know that they were subject of an experiment. As indicated by Levitt and List (2007), this feature avoids the bias caused in behavior when subjects are aware of being actively monitored, increasing the validity of the results. In addition, this assures that strategic effects are not muted in response to being treated. This contrast with many experiments in which it is purposively indicated to the experiment participants that the experiment is a one-shot event (or that randomizes pairs of players in each round), in order to avoid contamination from strategic effects. While useful to uncover direct effects, this practice prevents measurement of the complete effect of the incentive scheme.

\section{Empirical analysis}

\subsection{Data and variables}

We obtained data from the administrative records of C.CCU. We collected information for the 53 salespersons that participate in our experiment. This data covers sales and goals (in liters) for each product category for 25 consecutive months prior to the experiment, from to July-11 to July-13, and for the experimental period itself, August and September 2013. Adding historical information allows us to compute a key independent variable in our analysis, "goal ratcheting". In figure 2 we present the ratio of sales to goals for the two categories of interest -wine and spirits-, for the period prior to the experiment.

Besides sales and goals for the different product categories, we use several salespersons characteristics as control variables in our analysis. First, we obtained worker tenure. This variable is measured in months by subtracting the month in which each salesperson signed a formal labor contract with CCU from the month " $t$ ", the periods of our dataset. The blue line of figure 3 presents a kernel density plot for the tenure variable from periods 1 to 25 . Salespersons that start working for C.CCU have, on average, a one year period in which they are under evaluation and no formal long term contract is signed; this explains why negative tenure exists in our dataset. This group corresponds roughly to the first decile of the distribution. Importantly, the rotation of this group is much larger (around 60\% a year) than for salespersons that have 
signed a contract (around 3\%). Given that this may affect the behavior of salespersons, we include a control variable that takes the value of one for this first decile and zero otherwise.

The second variable we include as control is the (hiring) origin of the salespersons. There are two different sources for the salespersons in our dataset. Approximately fifty five percent of the salespersons were hired by C.CCU after its creation in 2005. The rest worked for one of the four product division of CCU and were transferred to C.CCU from 2005 onwards. The latter group sold only one type of product category prior to 2005. As shown in figure 3, tenure differs importantly between these two types of workers: In the red line we show the tenure of salespersons with its origin in C.CCU and in the green line we show salespersons with its origin in the one of the product division, prior to the birth of C.CCU. Our variable controlling for the origin of salespersons is a dummy variable taking the value of 1 when the salesperson has its origin in $\mathrm{CCU}$ and 0 otherwise.

The third control variable in our analysis is the performance evaluation that salespersons receive each year. Each February, salespersons are classified, based on the performance of the prior year, in one of six categories: "in development", "competent (-)", “competent", “competent (+)", "superior (-)" and "superior". Goal attainment in different product categories is part of this evaluation, furthermore the classification that a worker received might affect his/her behavior towards goal attainment. We created a dummy variable taking the value of 1 if the salespersons was given a rate of "competent (+)", "superior ()" or "superior" and 0 otherwise ${ }^{14}$.

The last control variable we include is the experience of the salesperson with its supervisor. This variable is measured for each pair of salesperson and supervisor by counting the number of consecutive months they have worked together. It is important to account for supervisor turnover prior to the experiment, and thus heterogeneity in common experience. We do not have information prior to July 2011, so our variable is left-censored. However, the inclusion of salesperson fixed effects in our analyses allows circumventing this problem.

\footnotetext{
${ }^{14}$ We also tested including a dummy set of all the categories of the performance rating. Results did not change.
} 
In table 1 we present the summary statistics and the correlation matrix for the variables described so far. In table 2 we compare these variables across our geographic zones, north (regions of Antofagasta and Calama) and south (Regions of Valdivia and Temuco)

[Insert figure 2 and 3 and tables 1 and 2 around here]

\subsection{Goal ratcheting measurement}

Sales supervisors have freedom to set the goals of the salespersons under their supervision and have complete information on prior salespersons performance. We are interested in testing if they use this information in order to ratchet the salespersons' goals.

To estimate goal ratcheting we used the following econometric model, using, for consistency, only wine and spirits as the $j$ product categories (see section 5.3.1 for a robustness check):

$$
\frac{\text { Goal }_{i, j, t-\text { Goal }_{i, j, t-1}}}{\text { Goal }_{i, j, t-1}}=\rho_{0}+\rho_{1} \cdot \frac{\text { Sales }_{i, j, t-1}-\text { Goal }_{i, j, t-1}}{\text { Goal }_{i, j, t-1}}+\gamma_{i, j}+\delta_{t}+\mu_{i, j, t}
$$

In this model, $\rho_{1}$ captures the extent of goal ratcheting in the whole sample. This is equivalent to estimating (where $\rho_{0}{ }^{\prime}$ will be equal to $\rho_{0}+\rho_{1}+1$ ):

$$
\frac{\text { Goal }_{i, j, t}}{\text { Goal }_{i, j, t-1}}=\rho_{0}^{\prime}+\rho_{1} \cdot \frac{\text { Sales }_{i, j, t-1}}{\text { Goal }_{i, j, t-1}}+\gamma_{i, j}+\delta_{t}+\mu_{i, j, t}
$$

We require variation in our sample with respect to the level of ratcheting on salespersons. Therefore we need to estimate a ratcheting parameter for each sales supervisor " $k$ ". To do so, we estimate the following econometric model:

$$
\frac{\text { Goal }_{i, j, t}}{\text { Goal }_{i, j, t-1}}=\rho_{0}{ }^{\prime}+\rho_{1} \cdot \text { Sales }_{i, j, t-1}^{\text {Goal }_{i, j, t-1}}+\sum_{k=1}^{\mathrm{K}} \rho_{1, k} \cdot \frac{\text { Sales }_{i, j, t-1}}{\text { Goal }_{i, j, t-1}} \cdot \text { Supervisor }_{k}+\varphi_{k}+\gamma_{i, j}+\delta_{t}+\mu_{i, j, t}
$$

In this model, we control for seasonality by including time fixed effects and we control for unobserved heterogeneity at the joint salespersons and product type level by including the dummy set $\gamma_{i, j}$. We estimated equation (7) using periods 1 to 25 . In the next section, we use these estimates to disentangle the direct and strategic effects of the goal variations introduced in our experiment in periods 26 and 27.

The results of this estimation are presented in table 3. Given that we have some turnover in supervisors, we have estimates of goal ratcheting for 14 supervisors from period 1 (Jul-11) to 25 (Jul-13), even though 
at any point in time we have only 9 supervisors. The distribution of ratchet effect is depicted in figure 4 . Goal ratcheting goes from a minimum of $13 \%$ to a maximum of $100 \%$, with a near to uniform progression among these extremes. The average level of goal ratcheting is $60 \%$. Beneath each identifier of supervisor we present in parentheses the amount of observations using in the estimation of the ratchet effect and the symbol * denotes that the supervisor did not last until the periods 26 and 27.

In the experiment we only create exogenous variance in goals, and not in the expectation of goal ratcheting. If there is endogenous matching between salespersons and supervisors this might confound our identification of causality. However, there are two reasons to believe the there is an exogenous matching process in our setting.

First, from interviews to executives and regional managers we were informed that there is not an institutionalized (neither formal nor informal) process by which salespersons might select or "apply" for specific supervisors. However, informal matching over time might still take place.

Second, we test to see if salespersons with different levels of goal ratcheting have different observables. In table 4 we present a comparison between salespersons that have a high and low ratcheting supervisor (we only consider supervisors present in the experimental periods) along with statistical test measuring the difference. We present two cut-off of high/low ratchet because we have 9 supervisor and different cut-offs generate non symmetrical subsamples of 23 and 30 on each side. We find that in 10 out of 16 tests there is no statistically significant difference and in only one variable out of eight (experience with supervisor) there was significant difference in both cut-offs. From this we conclude that although there are some statistical significant differences, the groups seem sufficiently similar. Importantly, the almost identical tenure between the two groups suggests that ratchet behavior is not related to turnover, which might be a key mechanism of sorting between salespersons and supervisors. In contrast, the difference between the groups in the variable of experience between salespersons and supervisors suggests that ratcheting may be related to supervisor turnover.

[Insert tables 3 and 4 and figure 4 around here] 


\subsection{Experiment Results}

To test the overall effect of the experimental variation on goals on salespersons behavior, we use the following model:

$$
\frac{\text { Sales Wine }_{i, t}}{\text { Sales Spirits }_{i, t}}=\alpha_{0}+\alpha_{1} \cdot D_{-} \text {TREAT }_{i, t}^{\text {HIGH_WINE }}+\alpha_{2} \cdot D_{-}{ }_{\text {TREAT }}^{\text {HIGH_SPIRITS }}+\theta_{i}+\delta_{t}+\mu_{i, t}
$$

In this model, D_TREAT ${ }_{i, t}^{H I G H_{-} W I N E}$ is a dummy that takes the value of 1 when the salesperson " $i$ ” is in a region that in period " $t$ " experienced the treatment of a $15 \%$ increase in the goal of wine (and $15 \%$ decrease in the goal of spirits) and a 0 otherwise. Analogously, $D_{-} T R E A T_{i, t}^{H I G H \_S P I R I T S}$ is a dummy that takes the value of 1 when the salesperson " $i$ " is in a region that in period " $t$ " experienced the treatment of a $15 \%$ increase in the goal of spirits (and 15\% decrease in the goal of wine) and a 0 otherwise. Using

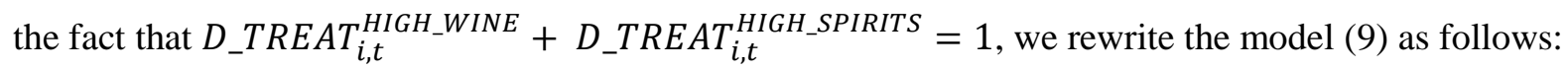

$$
\frac{\text { Sales Wine }_{i, t}}{\text { Sales Spirits }_{i, t}}=\left(\alpha_{0}+\frac{\alpha_{1}+\alpha_{2}}{2}\right)+\left(\frac{\alpha_{1}-\alpha_{2}}{2}\right) \cdot \text { DIF_TREAT }_{i, t}+\theta_{i}+\delta_{t}+\mu_{i, t}
$$

Here, DIF_TREAT $T_{i, t}$ is defined as $D_{-} T R E A T_{i, t}^{H I G H_{-} W I N E}-D_{-} T R E A T_{i, t}^{H I G H_{-} S P I R I T S}$, and takes the value of 1 if the goal of wine is increased $15 \%$ and spirits decreases in $15 \%$ and the value of -1 if the goal of spirits is increased $15 \%$ and spirits decreases in $15 \%$. Thus, a one unit increase in DIF_TREAT is equal to evaluating the treatment of increasing in $(1+15 \%) /(1-15 \%)-1$ the ratio of wine goal to spirits goal. Since the direct effect predicts that $\alpha_{1}<0$ and $\alpha_{2}>0$ in equation (9), in equation (10) we are, in essence, averaging $\alpha_{1}$ and $\alpha_{2}$. Using equation (10) is better than equation (9) because each salespersons is subject to both of these treatments, and thus we should not expect any difference between $\alpha_{1}$ and $\alpha_{2}{ }^{15}$.

The results for equation (10) are presented in models 2, 3 and 4 of table 5 using OLS, fixed effects and a random trend, respectively. The estimate using FE and a random trend do no differ from the OLS results, supporting the exogeneity of our experimental variation. The value of the coefficient $\left(\frac{\alpha_{1}-\alpha_{2}}{2}\right)$ is not

\footnotetext{
${ }^{15}$ We estimated equation (9) and we couldn't reject the hypothesis that the absolute value of $\alpha_{1}$ and $\alpha_{2}$ were equal. This lack of difference confirms the notion that $\left|\alpha_{1}\right|$ and $\left|\alpha_{2}\right|$ are measuring the same behavioral response.
} 
significantly different from zero. Results are robust to clustering standard errors by supervisor, geographical area and region (available upon request).

This result is indicative of the presence of a strategic effect that might be offsetting a direct effect. To test for the presence of strategic effect we interact the treatment with the expectation of goal ratcheting. Here we assume that the historical ratcheting behavior of the sales supervisor is a good predictor of the salespersons's expectations of future ratcheting.

We explore the presence of a strategic effect using the following model:

$$
\begin{aligned}
{\frac{\text { Sales Wine }_{i, t}}{\text { Sales Spirits }_{i, t}}} & \left(\alpha_{0}+\frac{\alpha_{1}+\alpha_{2}}{2}\right)+\left(\frac{\alpha_{1}-\alpha_{2}}{2}\right) \cdot \operatorname{DIF}_{\text {TREAT }_{i, t}}+\alpha_{3} \cdot \operatorname{DIF}_{\text {TREAT }_{i, t}} \cdot Z_{i, t}+\alpha_{4} \cdot Z_{i, t}+\theta_{i}+ \\
& \delta_{t}+\mu_{i, t}
\end{aligned}
$$

In vector $\mathrm{Z}$ we included the goal ratcheting behavior of the sales supervisor and control variables which we describe in section 5.1 above. We interact the control variables with DIF_TREAT to increase the "control effect" that they can exert on the interaction between DIF_TREAT and goal ratcheting. This is particularly important since we do not have clear exogeneity in the ratcheting variable.

In model 5, we present the results without introducing control variables. Consistent with the predictions of our model, we obtain a positive and significant coefficient for the interaction term between the treatment and the goal ratcheting, and a negative and significant coefficient for the individual term of our treatment variable. This result shows that if the supervisor does not have a history of goal ratcheting the salesperson will display only the direct effect and, as the supervisor increases his historical record of goal ratcheting, the strategic effect kicks in, counteracting the direct effect.

In model 6 we check for robustness to the inclusion of control variables. The results strengthen with their inclusion: the magnitude of coefficient of DIF_TREAT increases from -0.24 to -0.42 and the coefficient of the interaction with goal ratcheting increases from 0.50 to 0.62 (however, these differences are not statistically significant). The results of the model 6 are depicted in the figure 5 , where we vary the amount of goal ratcheting from $0 \%$ to $100 \%$. When there is no ratchet, a $10 \%$ increase in the ratio of goals produces a decrease in the ratio of sales of $10.4 \%$. This result is supportive of our prediction \#1. In contrast, 
when ratchet is $100 \%$, a $10 \%$ increase in the ratio of goals produces an increase in the ratio of sales of $7.3 \%$. This result is supportive of prediction $\# 2^{16}$.

To correct for the possibility that standard errors are not independent, we tested a model including clustering at the supervisor level (available upon request). Goal ratcheting is measured at the supervisor level and thus we may be underestimating our standard errors. We estimated the correct standard errors using the wild bootstrap correction method which is suited to deal with a low numbers of clusters, in our case - few supervisors (see Cameron and Miller, 2015 for details). The result we obtained from the bootstrapping shows that the coefficient for the interaction term between DIF_TREAT and ratcheting has a $95 \%$ percent confidence interval is $[0.08,1.16]$. The bootstrapping of the Wald t-test lead to a p-value of this coefficient of 0.14 (two-sided) and 0.07 (one-sided), which, as expected, is larger compared to the pvalue of 0.04 (two-sided) and 0.02 (one-sided) from model 5. The implied increase in the variance of the coefficient is approximately $40 \%$. Thus, even though some significance is lost, we still obtain statistically significant results from the one-sided test.

Inclusion of control variables yields some interesting results. The coefficient of the interaction of these variables with the DIF_TREAT can be interpreted as a change in the strength of the direct effect, that is, as shifting the baseline coefficient of "difference in treatment". If the coefficient of the interaction is positive, as in the interaction with performance evaluation, then the direct effect becomes smaller; the opposite occurs with a negative coefficient, the direct effect becomes stronger. Control variables can modify the direct effect through two mechanisms.

First, in CCU there are some costs of displaying a strong direct effect -that is, not complying with goals. The incidence and impact of these costs can be modified by the control variables. These costs are generated, for example, because the internal supply chain -production and logistics- performs better if

\footnotetext{
${ }^{16}$ Since the ratcheting coefficients are measured with error, this could affect the estimates displayed in table 5. Using the estimated standard deviation of the ratcheting coefficients, we executed an errors-in-variable regression to explore the incidence of this problem. As expected, we found that both the size and the standard deviation of the coefficient of "Difference in treatment X Goal ratcheting" increased, maintaining its statistical significance at the 5\% level. Considering model 5, the coefficient increased from 0.501 to 0.574 .
} 
variance is reduced by consistently meeting goals. Company executives also inform that the relation with the business units' marketing areas run smoother when goals are consistently met. These costs could eventually lead to penalizing salespersons that are not compliant with goals. It is not surprising then to find that the company documents -for the population of salespersons- a positive relation, yet small, between meeting goals and performance evaluation.

Second, the control variables can affect the time discount of salespersons. For example, if the discount is larger, then the second period weights less and thus the choices are affected mostly by current concerns. This could lead to a higher prevalence of the direct effect.

We find that having less than a year of tenure (i.e., being in the $10^{\text {th }}$ decile of tenure), being a legacy salesperson (not having origin in the SSU) and having a lower performance appraisal in the previous year are related to a higher direct effect. In figure 6 and in figure 7 we graph the impact of tenure and origin, respectively.

There are motives to think that having a lower tenure, being a legacy salesperson and having a lower performance evaluation could be related to lower cost of non-compliance and to higher time discounting. First, the salespersons in their first year have a rotation of $60 \%$, which then drops to $3 \%$. Thus, the costs of non-compliance and any concerns about the future are much less of an issue. We expand on the analysis of tenure result in the next section, where we study in more detail the entire distribution of tenure deciles using historical information. Second, legacy salespersons have stronger "shields" against the firm's reaction to a noncompliant behavior. Comparatively, this group has $20 \%$ higher wages (for historical reasons) and they are strongly unionized (while the other group is not). We speculate that these two factors allow the salespersons in this group to be less worried about costs of non-compliance. Third, performance evaluation is positively related to reaching goals and thus a lower performance evaluation can be seen as a proxy for compliance costs; also, a lower performance evaluation may signal a higher likelihood of termination and thus a higher time discount.

[Insert table 5 and figures 5, 6 and 7 around here] 
5.3.1. Robustness check using alternative measures for ratcheting. Supervisor goal ratcheting behavior is not restricted to wine and spirits. It might be argued that how supervisors ratchet the goals in soft drinks and beer categories is more relevant to salespersons behavior. After all, beer and soft drinks are much more important for overall sales. To explore this possibility we measured the goal ratcheting behavior for these two major categories using the same procedure as in section 5.2. Interestingly, even though goal ratcheting in beer/soft-drink has roughly the same mean, standard deviations and range as goal ratcheting in wine/spirits, the correlation coefficient between these two types of ratcheting is -0.06 . This suggest that ratcheting behavior of supervisors is subtle, instead of applying ratcheting across all categories, they seem to adopt different ratcheting strategies across the two broad categories (some do both types, some do only one type, some do neither of them).

In table 6 we present our results introducing the new measure of ratcheting in our treatment regressions. The estimates of model 7 show that salespersons react with a stronger strategic effect (i.e., the ratio of sales in wine to spirits increases in response to an increase in their goal ratio) when their supervisor is doing more ratcheting in the soft drink and beer categories. In addition, the estimates of model 8, where we include two interactions, one for each type of ratcheting behavior, show that the reaction to the ratcheting in wine/spirit we documented earlier in table 5 is robust to the inclusion of the interaction with ratcheting in beer/softdrink, which also remains significant. This result shows that salespersons react to both types of ratcheting behavior at the same time, that is, the strategic effect in wine/spirit is a reaction to goal ratcheting not only in the wine/spirit categories but also in the beer/soft-drink categories. The implication of this is that those salespersons whose supervisors are executing high ratcheting in all the product categories will display a much higher strategic effect. This is exactly what we found in the model 9, where we created a "hybrid" measure of ratcheting, weighting equally our two previous measures. As expected, the amount of strategic behavior increases, doubling in size.

[Insert table 6 around here]

5.3.2. Drivers of ratcheting behavior. Although exploratory and descriptive, we studied which variables might be correlated with the ratcheting behavior of supervisors (this analysis is available upon 
request). There is scarce evidence on this issue in the extant research. First, using equation (8), we estimated 5 ratchet coefficients, one for each product category for each sales supervisor. Then, we collected several measures that might explain the ratcheting behavior: the age and the performance evaluation of each supervisor; the market share and the loyalty of customers of the city where the supervisor works (drawn from a market research survey of the company); and several characteristics of the salespersons that comprise the supervisor's team (average origin, average performance evaluation, average size, average tenure, average experience with the supervisor).

We found that in cities with more market share and higher loyalty the ratcheting coefficient is higher. We also found that the ratcheting coefficient is higher in the beer category, where CCU commands $79 \%$ market share, much higher than in the others categories (30\% soft drink, $27 \%$ wine, $37 \%$ spirits, $2.5 \%$ confectionary). These two results indicate that, as expected by the arguments and lab evidence from Charness et al (2011), competition is negatively correlated with ratcheting. The intuition is that, given some firm and industry specificity of workers, a higher market share lowers their external alternatives, allowing the principal to extract more surplus through ratcheting.

Surprisingly, variables related to the supervisor and to its team of salespeople were not strongly correlated with ratcheting behavior. Only one variable was the exception: we found that ratcheting was negatively correlated with the average performance evaluation of its team. This is consistent with the standard prediction that high ratcheting decreases the motivation and effort of salespeople. However, given that the supervisor importantly informs its team's performance evaluation, this correlation could be due to omitted variables at the supervisor level (e.g., a tendency "put down" its salespersons).

\subsection{Exploring tenure dynamics using historical data}

The dynamics of a worker's response to changes in goals may be obviously subject to changes over time, particularly, over tenure. For example, salespersons may learn the rules of the game gradually, and thus they may adapt their strategic responses accordingly. To assess if there is some dynamics in our setting, in this section we analyze the historical data to cover a larger time span. For periods 1 to 25, we first use the 
following simple model to see if the non-experimental estimate is consistent with the experimental effect of model 2 and 3 of table 5:

$$
\frac{\text { Sales Wine }_{i, t}}{\text { Sales Spirits }_{i, t}}=\beta_{0}+\beta_{1} \cdot \frac{\text { Goal Wine }_{i, t}}{\text { Goal Spirits }_{i, t}}+\theta_{i}+\gamma_{t}+\mu_{i, t}
$$

In this fixed effects panel data model, the ratio of sales of wine to sales of spirits for each salesperson "i" in month " $\mathrm{t}$ " is explained by the ratio in goal of wine to goal the goal in spirit. Here, goals are the actual goals that sales supervisor set historically, so they are endogenous. If supervisors set goals with foresight, and this foresight can predict actual sales, there will be a positive bias in our estimation of $\beta_{1}$. We can partially avoid this bias by adding a trend for each salesperson on top of the level captured by $\theta_{i}$. This is done by adding the term $g_{i} \cdot t$ to the econometric specification. This model is known as the "random-trend model":

$$
\frac{\text { Sales Wine }_{i, t}}{\text { Sales Spirits }_{i, t}}=\beta_{0}+\beta_{1} \cdot \frac{\text { Goal Wine }_{i, t}}{\text { Goal Spirits }_{i, t}}+\theta_{i}+g_{i} \cdot t+\gamma_{t}+\mu_{i, t}
$$

Exploiting the fact that $g_{i} \cdot t-g_{i} \cdot(t-1)=g_{i}$, we obtain the following model in differences that can be estimated using a traditional fixed effect estimation technique,

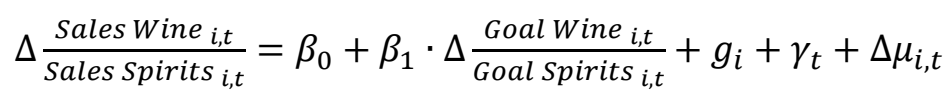

In models 10, 11 and 12 of table 7 we present the OLS, the fixed effects and the random trend estimation of the above models. Consistently with the presence of a bias, the results show a positive and significant coefficient for the OLS estimation, but a non-significant coefficient for the fixed effect and random trend. Moreover, the results are consistent with the experimental test, indicating an average response of zero. This provides some confidence in exploring the dynamics of behavior over tenure using the following specification:

$\frac{\text { Sales Wine }_{i, t}}{\text { Sales Spirits }_{i, t}}=\beta_{0}+\beta_{1} \cdot \frac{\text { Goal Wine }_{i, t}}{\text { Goal Spirits }_{i, t}}+\beta_{2} \cdot \frac{\text { Goal Wine }_{i, t}}{\text { Goal Spirits }_{i, t}} \cdot Z_{i, t}+\beta_{3} \cdot Z_{i, t}+\theta_{i}+\gamma_{t}+g_{i} \cdot t+\mu_{i, t}(14)$

In this specification we include all the control variables included in the experiment. We also include ten dummies, one for each tenure decile we observe in our data. The blue line of figure 3 depicts the 
distribution of tenure for the complete set of salespersons in our sample. In the model 13 and 14 of table 6 we present the coefficient estimates.

The results show a clear pattern. In both models we find that the slope between the ratio of goals and the ratio of sales is: i) significant and strongly negative for the first tenure decile, ii) non-significant and close to zero for the $20^{\text {th }}$ decile to the $60^{\text {th }}$ decile, and iii) significant and positive for the $70^{\text {th }}$ to $100^{\text {th }}$. In the figure 8 we graphically show how the slope varies across different tenure deciles. A striking result is the strength of the negative slope for the first decile ${ }^{17}$.

What might account for this effect? We believe that the answer is a mix of two effects: getting hired by C.CCU and learning from supervisors or colleagues about the ratchet effect. With respect to the former, salespersons in the first tenure decile have a $60 \%$ yearly rotation rates -compared to a $3 \%$ for the rest of salespersons- which as discussed above, leads to a higher direct effect through lower non-compliance costs and a lower time discount factor $\delta$.

Another potential explanation is that it takes time for workers to learn the ratcheting behavior of their supervisors and thus, tenure would be related to the strategic effect. To explore this idea, we executed a non-reported model with experimental data using a triple interaction model, where we interact DIF_TREAT, $10^{\text {th }}$ decile and ratchet (including the complete set of double interactions) (available upon request). We obtain a strong negative coefficient for the triple interaction term which means that salespersons which are in the first decile will not be affected as strongly by goal ratcheting than older salespersons. In short, this suggests that the strategic effect of a positive coefficient for ratchet takes time to be learned. However, the result obtained is strong in economic terms but only significant with $80 \%$ confidence. Power is low when testing a triple interaction in our experiment; however the sign and magnitude are consistent with a learning argument.

[Insert table 7 and figure 8 around here]

\footnotetext{
17 The results of table 7 are not affected by endogenous attrition concerns, that is, if formal contracts after a year are awarded only to complying salespersons, then our result could be entirely driven by selection. Our historical data tracks exclusively the salespersons that are present in the experiment. Although this might generate a small noise in measuring the ratcheting behavior, our results are robust the correcting for noise in the ratcheting measure.
} 


\section{Discussion and Conclusion}

We developed a formal model to predict the behavior of a multiproduct sales force subject to differing amounts of incentive ratcheting behavior and confirm our predictions using a field experiment. First, we find that salespersons increase (decrease) sales in the product category for which effort is more (less) valuable, namely in the category that had an exogenous decrease (increase) in its goals. This result is highly consistent with the presence of a strong direct effect.

Second, we found evidence of strategic behavior in salespersons. If the salespersons have learned that increments in sales lead to higher goals in future periods (i.e., goal ratcheting), then they adjust their present behavior leading to the opposite result: sales increased (decreased) in the category that experienced the exogenous increase (decrease) in goals. Our model suggests that this compliant behavior with goals is a result of rational maximizing behavior and not obtained from other behavioral forces.

Third, the average response to changes in goals across salespersons was null. This null response covers a high level of heterogeneity in strategic behavior, and was not due to non-responsiveness to incentives by the sales force. On the contrary, we show that salespersons are highly sophisticated in their response to incentives. This result suggests that a deeper understanding of strategic effects may help parse out potential interpretations of average non-responsiveness to changes in incentives that have been documented in the literature (cf. Prendergast, 2015).

Finally, we also explore heterogeneity in our findings. First, we find that our results vary systematically with tenure. During their first year at the company workers behave as if there was no ratcheting or they didn't care about the future. This can be explained by a combination of forces: on the one hand, it takes time for employees to learn about the ratcheting practice of its supervisors, modifying the salience of the strategic effect; on the other, a higher expected turnover during the first year increases the direct effect by limiting the costs of non-compliance and the weight of future periods. Second, our results related to origin and performance appraisal suggest that the direct effect is stronger when salesperson are better protected from firm retaliation related goal compliance (i.e., less subject to non-compliance costs). 
Our results have important managerial implications. First, they show that managers must pay attention not only to the design of the incentive scheme but also on the procedures used to update parameters of the system such as goals and incentive slopes. In our setting, delegating the decision of goals across salespersons to their supervisors may have very different effects depending on the supervisors. If supervisors understand the value of commitment and avoid ratcheting it has the advantage that the local knowledge of supervisors can be used to set better goals. If supervisors are myopic and engage in ratcheting the salesforce becomes unresponsive to monetary incentives. As many case studies like the famous Lincoln electric case suggest, these mechanisms may in many circumstances need to rely on relational rather than formal contracts (see for example Bol and Lill, 2015).

Second, our results show that employees can be highly sophisticated in their response to incentive schemes and that although some rules and uses (like ratcheting) are largely informal, employees quickly learn from them and incorporate them in their decision process. This stresses the need for great care in the design and implementation of any compensation scheme and also presents a challenge when trying to measure their effectiveness.

Our paper also contributes to two research streams: literature on "goals and incentives" (beyond ratcheting) and literature on "incentives for multiproduct sales force".

There is an extensive literature on goals as incentive mechanisms, mainly from psychology. Some studies have shown that goals can promote motivation and increase performance when they are specific and difficult to achieve (Locke and Latham, 2002 and 2006). Goals achieve this result by activating the intrinsic motivation of workers even when the achievement of goals is not associated with bonus or other forms of compensation. In contrast, the economics literature has only recently started to address the issue of goals and its impact on worker motivation. Standard agency theory suggests that goals shouldn't affect effort beyond their instrumental value. However, more recent evidence in behavioral economics has shown that moderately difficult wage-irrelevant goals increase effort by agents (Georg and Kube, 2012). Similarly, goals have been rationalized as a reference point for workers effort (Heat et al, 1999; Abeler et al, 2011) or as solutions to worker's problem of self-control (Hsiaw, 2013; Kaur et al, forthcoming; Jain, 2012). 
Notwithstanding, the way in which goals interact with monetary incentives have not been extensively studied, in psychology and economics. Typically, psychology abstracts from monetary incentives and the latter focus on extrinsic and not on intrinsic motivation. The recent contribution by Corgnet et al (2015) and Anderson et al (2010) are an important step forward in bridging this gap. The former analyzes how wage-irrelevant goals interacts with monetary incentives and they found that there is a complementary relation between them, that is, the effort inducement of goals is higher when paired with a monetary incentive that is not influenced by the goal ${ }^{18}$. The latter shows how having a participative goal setting process between principal and agent can affect the type of goals being selected and the ensuing behavior by agents.

We contribute to the goal literature by noticing that in many settings goals carry monetary consequences for workers. Goals in general are not wage-irrelevant; instead, they interact with monetary payments and this can severely alter the conclusions drawn from previous research. This is particularly true in sales force management. Sinha and Zoltners (2001) and Zoltners et al (2006) show that $82 \%$ of sales forces have goalbased incentives schemes. Our results show that in these cases not only are monetary rewards important (via the direct effect), but the agent's expectation regarding the dynamics of goal setting is necessary to regard goals as motivators (the strategic effect). We believe that how formal incentives interact with goals and goal the setting processes in general remains a major question to be explored.

We also contribute to the literature on incentives in multiproduct salesforces. According to the review by Mantrala et al (2010) there is scant theoretical work, and even fewer empirical studies, regarding the optimal incentive structure for multiproduct salesforce. Concretely: i) Farley (1964) argues that the same commission rate should be applied across the contribution margin of product categories, and Berger and Jaffe (1991) state that if agents are risk averse, a higher commission on margin should be used on products with lower demand variability, ii) if commission rate on margins are not available, Lal and Srivanansan (1993) suggest using a larger commission rate on sales for those product categories with a higher effort-

\footnotetext{
18 There is also recent work in behavioral economics studying the extent to which economic incentives may crowd out intrinsic motivation (Gneezy et al, 2011; Frey and Jegen, 2001).
} 
sales elasticity and with a higher margin, iii) by introducing cross-selling patterns, Zhang and Mahajan (1995) suggest that complementarity among product categories requires setting the higher commission on sales on the product with higher effort-sales elasticity, substitution among product categories requires setting a commission on the pooled sales, and independence requires an individual sales commission on each product category.

We contribute to this literature by highlighting that goal setting behavior across categories can importantly change effort allocation across product categories. Poor forecasting can distort optimal effort provision across categories and goal ratcheting may mute incentives to optimize sales effort across categories.

Our study has limitations. First, our evidence is drawn from a unique firm, limiting the extent to which our findings can be generalized. Second, we have exogenous experimental variation on the incentives structure (to identify the direct effect), but the variation on the expectations of change in the incentive structure is taken from historical data. Coming up with a practical way to introduce experimental variation on ratcheting expectations on the field is an interesting challenge for future research. Finally, since goals convey information about what the principal wants, changes in goals may carry more information about what is expected from the agent than other types of changes to the incentive structure, such as changes in payout function, measures, weights or piece rates. It would be interesting to see, for example, if ratcheting at the weights (rather than at goals) affects the results.

\section{Acknowledgments}

We would like to thank the Editor, Associate Editor, two anonymous referees, Tomasz Obloj, participants at SIOE Conference in Paris 2015 and Judge Business School Core Conference 2016 and seminar participants at FGV Sao Pablo and Catholic University of Chile for helpful comments and suggestions.

\section{References}

Abeler, J., A. Falk, L. Götte, \& D. Huffman. (2011). Reference points and effort provision. American Economic Review, Vol. 101, No. 2, pp. 470-92. 
Anderson, S., Dekker, H. Sedatole, K. (2010) An Empirical Examination of Goals and Performance-toGoal Following the Introduction of an Incentive Bonus Plan with Participative Goal Setting. Management Science 56(1):90-109

Bandiera, O., Barankay, I., Rasul, I. (2005). Social preferences and the response to incentives: Evidence from personnel data. The Quarterly Journal of Economics, 917-962.

Bandiera, O., Barankay, I., \& Rasul, I. (2011). Field experiments with firms. The Journal of Economic Perspectives, 63-82.

Bellemare, C., Shearer, B., (2014) Measuring Ratchet Effects within a Firm: Evidence from a Field Experiment Varying Contractual Commitment, IZA Discussion Papers, No. 8214

Berger, P., Jaffe, L. (1991). The Impact of Risk Attitude on the Optimal Compensation Plan in a MultiProduct Situation The Journal of the Operational Research Society, 42, No. 4, pp. 323-330

Bol, J., Lill, J. (2015). Performance Target Revisions in Incentive Contracts: Do Information and Trust Reduce Ratcheting and the Ratchet Effect? The Accounting Review, In Press.

Bouwens, J., Kroos, P. (2011). Target ratcheting and effort reduction. Journal of Accounting and Economics, 2011, 51, no 1, p. 171-185.Cameron, A. C., \& Miller, D. L. (2015). A practitioner's guide to cluster-robust inference. Journal of Human Resources, 50(2), 317-372.

Charness, G., Kuhn, P., and Villeval, M. C. (2011). Competition and the Ratchet Effect, Journal of Labor Economics, Vol. 29, No. 3, pp. 513-547

Cooper, D., Kagel, J., Lo, W., Gu, Q. (1999). Gaming against Managers in Incentive Systems: Experimental Results with Chinese Students and Chinese Managers The American Economic Review, Vol. 89, pp. 781-804

Corgnet, B., Gómez-Miñambres, J., \& Hernán-Gonzalez, R. (2015). Goal Setting and Monetary Incentives: When Large Stakes Are Not Enough. Management Science. Articles in advance.

Farley, J. (1964). An Optimal Plan for Salesmen's Compensation, Journal of Marketing Research, 1(5): 3943.

Frey BS, Jegen R (2001) Motivation crowding theory. Journal of Economic Surveys 15(5): 589-611.

Gibbons, R. (1987). Piece-rate incentive schemes. Journal of Labor Economics, 51(1): 2-17

Gibbons, R., Roberts, J. (2013). Economic theories of Incentives in Organizations. Published in The Handbook of Organizational Economics, Ed. Gibbons, R., Roberts, J. Princeton University Press.

Gneezy U, Meier S, Rey-Biel P (2011) When and why incentives (don't) work to modify behavior. Journal Economic Perspectives 25(4): 191-210.

Goerg, S. and Kube, S., Goals (Th)at Work - Goals, Monetary Incentives, and Workers' Performance (October 1, 2012). MPI Collective Goods Preprint, No. 2012/19. Available at SSRN: http://ssrn.com/abstract=2159663 or http://dx.doi.org/10.2139/ssrn.2159663

Harrison, G., List, J. (2004). Field Experiments, Journal of Economic Literature, 42(4): 1009-1055.

Heat, C., Larrick, G., Wu, G., (1999). Goals as Reference Points, Cognitive Psychology, 38, 79-109.

Hsiaw A (2013) Goal-setting and self-control. Journal of Economic Theory 148(2):601-626.

Indjejikian, R. J., Matejka, M., \& Schloetzer, J. D. (2014). Target ratcheting and incentives: Theory, evidence, and new opportunities. The Accounting Review,89 (4), 1259-1267.

Jain, S., (2012). Self-Control and Incentives: An Analysis of Multiperiod Quota Plans, Marketing Science, Vol. 31, No. 5, pp. 855-869 
Jayaraman, R., Debraj, R. de Véricourt, F. (Forthcoming) Anatomy of a Contract Change, American Economic Review.

Kaur, S., Kremer, M., Mullanaithan, S. Forthcoming. Self-Control at Work. Journal of Political Economy, articles in advance.

Lal, R., Srinivasan, V. (1993). Compensation Plans for Single- and Multi-Product Salesforces: An Application of the Holmstrom-Milgrom Model, Management Science, Vol. 39, No. 7, pp. 777-793

Lazear, E., Oyer, P. (2013). Personnel Economics. Published in The Handbook of Organizational Economics, Ed. Gibbons, R., Roberts, J. Princeton University Press.

Levitt, S., List, J., (2007). What do laboratory experiments measuring social preferences reveal about the real world? Journal of Economic Perspectives, 21(2): 153-174

List, J. A., Sadoff, S., \& Wagner, M. (2011). So you want to run an experiment, now what? Some simple rules of thumb for optimal experimental design. Experimental Economics, 14(4), 439-457.

Locke, E. A., \& G. P. Latham. (2002). Building a practically useful theory of goal setting and task performance: A 35-year odyssey. American Psychologist, Vol. 57, pp. 705-717.

Locke, E. A., \& Latham, G. P. (2006). New directions in goal-setting theory. Current directions in psychological science, 15(5), 265-268

Mantrala et al (2010). Sales force modeling: State of the field and research agenda. Marketing Letters, 21: 255-272.

Mathewson, S. (1931). Restriction of output among unorganized workers. New York: Viking.

Murphy, K. J. (2001). Performance standards in incentive contracts. Journal of Accounting and Economics, 30(3), 245-278.

Obloj, T., \& Sengul, M. (2012). Incentive life-cycles learning and the division of value in firms. Administrative Science Quarterly, 57(2), 305-347.

Prendergast, C. (2015). The empirical content of pay-for-performance. Journal of Law, Economics and Organization, 31(2), 242-261.

Roy, D., (1952). Quota restriction and goldbricking in a Machine Shop”. American Journal of Sociology, 57: 427-442.

Sinha, P., Zoltners, A. (2001). Sales force decision models: Insights from 25 years of implementation. Interfaces, 31(3): 8-44.

Shearer, B. (2004). Piece rates, fixed wages, and Incentives: Evidence from a field experiment. Review of Economic Studies, 71: 433-444.

Weitzman, M. L. (1980). The "ratchet principle" and performance incentives. The Bell Journal of Economics, 302-308.

Zhang, C., Mahajan, V. (1995). Development of optimal salesforce compensation plans for independent, complementary and substitutable products, International Journal of Research in Marketing, 12(4): 355363.

Zoltners, A., Sinha, P., Lorimer, S. (2006), "The Complete Guide to Sales Force Incentive Compensation: How to Design and Implement Plans That Work”. New York: AMACOM 


\section{Tables and figures}

Table 1. Descriptive statistics and correlations matrix

\begin{tabular}{|l|l|r|r|r|r|r|r|r|}
\hline & 1 & 2 & 3 & 4 & 5 & 6 & 7 \\
\hline 1 & Sales Wine / Sales Spirits & 1.00 & & & & & & \\
\hline 2 & Goal Wine / Goal Spirits & 0.34 & 1.00 & & & & & \\
\hline 3 & Tenure (in months) & -0.01 & 0.07 & 1.00 & & & & \\
\hline 4 & Goal ratcheting & 0.09 & 0.15 & 0.07 & 1.00 & & & \\
\hline 5 & Salespersons origin in SSU & 0.09 & 0.09 & -0.76 & -0.01 & 1.00 & & \\
\hline 6 & High prior year performance evaluation & -0.03 & 0.02 & 0.47 & -0.04 & -0.37 & 1.00 & \\
\hline 7 & Experience with supervisor & -0.01 & 0.04 & 0.03 & 0.21 & 0.06 & 0.57 & 1.00 \\
\hline & & & & & & & & \\
\hline & Observations & 1292 & 1292 & 1292 & 1292 & 1292 & 1292 & 1292 \\
\hline & Mean & 2.88 & 2.68 & 74.56 & 0.60 & 0.55 & 0.41 & 9.45 \\
\hline & Standard deviation & 3.45 & 1.96 & 73.30 & 0.27 & 0.50 & 0.49 & 6.39 \\
\hline & Min & 0.00 & 0.09 & -17.93 & 0.13 & 0.00 & 0.00 & 1 \\
\hline & Max & 105.01 & 24.69 & 251.57 & 1.00 & 1.00 & 1.00 & 25 \\
\hline
\end{tabular}

Table 2. Descriptive statistics comparing geographical areas and periods.

\begin{tabular}{|l|l|l|l|l|}
\hline & \multicolumn{2}{|l|}{$\begin{array}{l}\text { Period 1 to 25 } \\
\text { (Pre-Experiment) }\end{array}$} & \multicolumn{2}{l|}{$\begin{array}{l}\text { Period 26 and 27 } \\
\text { (Experiment) }\end{array}$} \\
\hline Variable & North & South & North & South \\
\hline Number of salespersons per month & 26.4 & 25.2 & 27 & 26 \\
\hline Number of sales supervisors per month & 5 & 4 & 5 & 4 \\
\hline Monthly wine sales per salespersons (Liters) & 17.7 & 84.5 & 23.7 & 96.7 \\
\hline Monthly spirits sales per salespersons (Liters) & 9.6 & 28.5 & 9.81 & 32.4 \\
\hline Sales wine / Sales Spirits & 1.85 & 2.96 & 2.41 & 2.99 \\
\hline Monthly total sales per salespersons (Liters) & 1,399 & 1,463 & n/a & n/a \\
\hline Mean tenure (in months) & 57.5 & 92.4 & 69.9 & 103.3 \\
\hline Salespersons origin in SSU & $54.6 \%$ & $56.4 \%$ & $55.5 \%$ & $57.7 \%$ \\
\hline High performance evaluation & $22.7 \%$ & $59.4 \%$ & $37.0 \%$ & $69.2 \%$ \\
\hline Experience with supervisor & 9.11 & 9.80 & 15.07 & 17.76 \\
\hline
\end{tabular}

Table 3. Estimation of the amount of ratcheting of each supervisor.

\begin{tabular}{|c|c|}
\hline Dependent variable: (Goal in Category $\mathrm{j}$ in period $\mathrm{t}$ ) / (Goal in Category $\mathrm{j}$ in period $\mathrm{t}-1)$ & Model 1 \\
\hline Independent Variables: & Panel, FE \\
\hline (Sales in Category $\mathrm{j}$ in period $\mathrm{t}-1) /($ Goal in Category $\mathrm{j}$ in period $\mathrm{t}-1)$ & $0.525 * * *(0.046)$ \\
\hline (Sales in Category $\mathrm{j}$ in period $\mathrm{t}-1) /($ Goal in Category $\mathrm{j}$ in period $\mathrm{t}-1) *$ Supervisor \#1 & $-0.42 * * *(0.088)$ \\
\hline (Sales in Category $\mathrm{j}$ in period $\mathrm{t}-1) /($ Goal in Category $\mathrm{j}$ in period $\mathrm{t}-1) *$ Supervisor \#2 & $-0.302 \quad(0.311)$ \\
\hline (Sales in Category $\mathrm{j}$ in period $\mathrm{t}-1) /($ Goal in Category $\mathrm{j}$ in period $\mathrm{t}-1) *$ Supervisor \#3 & $-0.218 *(0.127)$ \\
\hline (Sales in Category $\mathrm{j}$ in period $\mathrm{t}-1) /($ Goal in Category $\mathrm{j}$ in period $\mathrm{t}-1) *$ Supervisor \#4 & $-0.210 * * *(0.071)$ \\
\hline (Sales in Category $\mathrm{j}$ in period $\mathrm{t}-1) /($ Goal in Category $\mathrm{j}$ in period $\mathrm{t}-1) *$ Supervisor \#5 & $\begin{array}{ll}-0.094 \quad(0.089) \\
\end{array}$ \\
\hline (Sales in Category $\mathrm{j}$ in period $\mathrm{t}-1) /($ Goal in Category $\mathrm{j}$ in period $\mathrm{t}-1) *$ Supervisor \#6 & $(0.071)$ \\
\hline (Sales in Category $\mathrm{j}$ in period $\mathrm{t}-1) /($ Goal in Category $\mathrm{j}$ in period $\mathrm{t}-1) *$ Supervisor \#7 & $-0.017 \quad(0.209)$ \\
\hline (Sales in Category $\mathrm{j}$ in period $\mathrm{t}-1) /($ Goal in Category $\mathrm{j}$ in period $\mathrm{t}-1) *$ Supervisor \#8 & (Omitted) \\
\hline (Sales in Category $\mathrm{j}$ in period $\mathrm{t}-1) /($ Goal in Category $\mathrm{j}$ in period $\mathrm{t}-1) *$ Supervisor \#9 & $0.012 \quad(0.145)$ \\
\hline (Sales in Category $\mathrm{j}$ in period $\mathrm{t}-1) /($ Goal in Category $\mathrm{j}$ in period $\mathrm{t}-1) *$ Supervisor \#10 & $(0.081)$ \\
\hline (Sales in Category $\mathrm{j}$ in period $\mathrm{t}-1) /($ Goal in Category $\mathrm{j}$ in period $\mathrm{t}-1) *$ Supervisor \#11 & $0.148 *$ \\
\hline (Sales in Category $\mathrm{j}$ in period $\mathrm{t}-1) /($ Goal in Category $\mathrm{j}$ in period $\mathrm{t}-1) *$ Supervisor \#12 & $0.186 * *(0.086)$ \\
\hline (Sales in Category $\mathrm{j}$ in period $\mathrm{t}-1) /($ Goal in Category $\mathrm{j}$ in period $\mathrm{t}-1) *$ Supervisor \#13 & $0.290 * \quad(0.173)$ \\
\hline (Sales in Category $\mathrm{j}$ in period $\mathrm{t}-1) /($ Goal in Category $\mathrm{j}$ in period $\mathrm{t}-1) *$ Supervisor \#14 & $0.473 * * *(0.047)$ \\
\hline Constant & $0.372 * * *(0.087)$ \\
\hline Year fixed effects? & YES \\
\hline Sales supervisor fixed effects? & YES \\
\hline Salespersons-category fixed effects? & YES \\
\hline
\end{tabular}




\begin{tabular}{|l|l|}
\hline Observations & 2,481 \\
\hline R-square & $70.20 \%$ \\
\hline $\begin{array}{l}\text { Standard Errors (in Parentheses): Robust and Clustered at the salespersons level, } ¥ 15 \% \text { significance level, * } 10 \% \\
\text { significance level, } * * 5 \% \text { significance level, ***1\% significance level }\end{array}$ \\
\hline
\end{tabular}

Table 4. Comparison of salespersons under high and low ratcheting in period 26

\begin{tabular}{|l|l|l|l|l|l|l|l|l|}
\hline Variable & $\begin{array}{l}\text { Low } \\
\text { Ratchet } \\
(<0.48)\end{array}$ & $\begin{array}{l}\text { High } \\
\text { Ratchet } \\
(>0.48)\end{array}$ & $\begin{array}{l}\text { Pearson } \\
\text { Chi-2 } \\
(\mathrm{p}-\text {-value })\end{array}$ & $\begin{array}{l}\text { T-test } \\
(\mathrm{p} \text {-value })\end{array}$ & $\begin{array}{l}\text { Low } \\
\text { Ratchet } \\
(<0.52)\end{array}$ & $\begin{array}{l}\text { High } \\
\text { Ratchet } \\
(>0.52)\end{array}$ & $\begin{array}{l}\text { Pearson } \\
\text { Chi-2 } \\
(\mathrm{p} \text {-value })\end{array}$ & $\begin{array}{l}\text { T-test } \\
(\mathrm{p}-\mathrm{value})\end{array}$ \\
\hline Number & 23 & 30 & & & 30 & 23 & \\
\hline Performance evaluation & - & - & $0.035^{* *}$ & & - & - & 0.373 & \\
\hline High performance evaluation & $69.5 \%$ & $40.0 \%$ & & $0.033 * *$ & $60.0 \%$ & $43.5 \%$ & & 0.240 \\
\hline Mean tenure (in months) & 86.25 & 85.44 & & 0.968 & 86.9 & 84.2 & & 0.893 \\
\hline Salespersons origin in SSU & $56.5 \%$ & $56.6 \%$ & & 0.991 & $53.3 \%$ & $60.8 \%$ & \\
\hline Percentage from north & $34.8 \%$ & $63.3 \%$ & & $0.040^{* *}$ & $50.0 \%$ & $52.1 \%$ & \\
\hline Monthly wine sales (Liters) & 53.1 & 69.4 & & 0.330 & 46.1 & 83.4 & & 0.878 \\
\hline Monthly spirits sales (Liters) & 24.5 & 18.8 & & 0.236 & 22.6 & 19.6 & & $0.022^{* *}$ \\
\hline Experience with supervisor & 11.9 & 18.9 & & $0.002 * * *$ & 11.4 & 21.7 & & 0.540 \\
\hline
\end{tabular}

Table 5. Regression analysis using experiment

\begin{tabular}{|c|c|c|c|c|c|}
\hline & \multicolumn{5}{|c|}{ Dependent variable: Sales Wine / Sales Spirits } \\
\hline & Model 2 & Model 3 & Model 4 & Model 5 & Model 6 \\
\hline $\begin{array}{ll} & \text { Method: } \\
\text { ependent Variables: } & \\
\end{array}$ & OLS & Panel, FE & $\begin{array}{l}\text { Panel, } \\
\text { Random } \\
\text { Trend }\end{array}$ & $\begin{array}{l}\text { Panel, FE, } \\
\text { w/interactions }\end{array}$ & $\begin{array}{l}\text { Panel, FE, } \\
\text { w/interactions }\end{array}$ \\
\hline \multirow{2}{*}{ Difference in treatment } & 0.040 & 0.040 & 0.019 & $-0.244 * *$ & $-0.425 * * *$ \\
\hline & $(0.187)$ & $(0.077)$ & $(0.083)$ & $(0.115)$ & $(0.145)$ \\
\hline \multirow[t]{2}{*}{$\begin{array}{l}\text { Difference in treatment } \mathrm{X} \text { Goal } \\
\text { ratcheting }\end{array}$} & & & & $0.501 * *$ & $0.624 * *$ \\
\hline & & & & $(0.228)$ & $(0.303)$ \\
\hline \multirow[t]{2}{*}{$\begin{array}{l}\text { Difference in treatment } \times 10^{\text {th }} \\
\text { tenure decile }\end{array}$} & & & & & $-0.385^{*}$ \\
\hline & & & & & $(0.214)$ \\
\hline \multirow[t]{2}{*}{$\begin{array}{l}\text { Difference in treatment } X \\
\text { Salespersons origin in SSU }\end{array}$} & & & & & $0.356 * *$ \\
\hline & & & & & $(0.159)$ \\
\hline \multirow[t]{2}{*}{$\begin{array}{l}\text { Difference in treatment X Prior year } \\
\text { performance evaluation }\end{array}$} & & & & & $0.227 *$ \\
\hline & & & & & $(0.114)$ \\
\hline \multirow[t]{2}{*}{$\begin{array}{l}\text { Difference in treatment } X \\
\text { Experience with supervisor }\end{array}$} & & & & & -0.010 \\
\hline & & & & & $(0.007)$ \\
\hline \multirow[t]{2}{*}{ Constant } & $2.689 * * *$ & $3.408 * * *$ & -0.555 & $3.408 * * *$ & $3.410 * * *$ \\
\hline & $(0.274)$ & $(0.324)$ & $(0.594)$ & $(0.324)$ & $(0.389)$ \\
\hline Period fixed effects? & YES & YES & YES & YES & YES \\
\hline Sales supervisor fixed effects? & $\mathrm{NO}$ & YES & YES & YES & YES \\
\hline Salespersons fixed effects? & NO & YES & YES & YES & YES \\
\hline Salespersons specific trend? & NO & $\mathrm{NO}$ & YES & NO & NO \\
\hline Individual terms of interactions? & $\mathrm{NO}$ & NO & $\mathrm{NO}$ & YES & YES \\
\hline Observations & 1398 & 1398 & 1344 & 1398 & 1398 \\
\hline R-square & $2.26 \%$ & $27.00 \%$ & & $27.07 \%$ & $27.14 \%$ \\
\hline
\end{tabular}

Table 6. Robustness check using alternative measure of ratcheting.

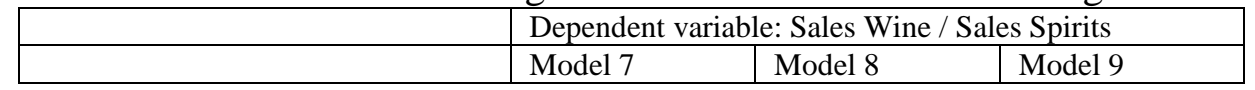




\begin{tabular}{|c|c|c|c|}
\hline Independent Variables: & $\begin{array}{l}\text { Panel, Random } \\
\text { Trend }\end{array}$ & $\begin{array}{l}\text { Panel, FE, } \\
\text { w/interactions }\end{array}$ & $\begin{array}{l}\text { Panel, FE, } \\
\text { w/interactions }\end{array}$ \\
\hline \multirow[t]{2}{*}{ Difference in treatment } & $-0.534 * *$ & $-0.798 * * *$ & $-0.831 * * *$ \\
\hline & $(0.243)$ & $(0.248)$ & $(0.250)$ \\
\hline \multirow{2}{*}{$\begin{array}{l}\text { Difference in treatment X Goal } \\
\text { ratcheting (Soft Drink and Beer) }\end{array}$} & $0.507 *$ & $0.547 *$ & \\
\hline & $(0.307)$ & $(0.279)$ & \\
\hline \multirow{2}{*}{$\begin{array}{l}\text { Difference in treatment } \mathrm{X} \text { Goal } \\
\text { ratcheting (Wine and Spirits) }\end{array}$} & & $0.640 * *$ & \\
\hline & & $(0.309)$ & \\
\hline \multirow{3}{*}{$\begin{array}{l}\text { Difference in treatment X "Hybrid" } \\
\text { Goal ratcheting }\end{array}$} & & & $1.224 * *$ \\
\hline & & & \\
\hline & & & $(0.520)$ \\
\hline $\begin{array}{l}\text { Difference in treatment X Controls } \\
\text { included? }\end{array}$ & YES & YES & YES \\
\hline Period fixed effects? & YES & YES & YES \\
\hline Sales supervisor fixed effects? & YES & YES & YES \\
\hline Salespersons fixed effects? & YES & YES & YES \\
\hline Individual terms of interactions? & YES & YES & YES \\
\hline Observations & 1398 & 1398 & 1398 \\
\hline
\end{tabular}

Table 7. Regression analysis using historical data

\begin{tabular}{|c|c|c|c|c|c|}
\hline & \multicolumn{5}{|c|}{ Dependent variable: Sales Wine / Sales Spirits } \\
\hline Model: & Model 10 & Model 11 & Model 12 & Model 13 & Model 14 \\
\hline Independent Variables: & OLS & Panel, FE & $\begin{array}{l}\text { Panel, } \\
\text { Random } \\
\text { Trend }\end{array}$ & $\begin{array}{l}\text { Panel, Random } \\
\text { Trend, } \\
\text { w/interactions }\end{array}$ & $\begin{array}{l}\text { Panel, } \\
\text { Random } \\
\text { Trend, } \\
\text { w/interactions }\end{array}$ \\
\hline \multirow[t]{2}{*}{ Goal Wine / Goal Spirits } & $0.610 * * *$ & -0.090 & -0.739 & -0.200 & $-0.526^{*}$ \\
\hline & $(0.082)$ & $(0.315)$ & $(0.725)$ & $(0.237)$ & $(0.270)$ \\
\hline \multirow[t]{2}{*}{ Goal Wine / Goal Spirits X $10^{\text {th }}$ tenure decile } & & & & $-2.035 * * *$ & $-1.887 * *$ \\
\hline & & & & $(0.732)$ & $(0.858)$ \\
\hline \multirow[t]{2}{*}{ Goal Wine / Goal Spirits X $20^{\text {th }}$ tenure decile } & & & & 0.089 & 0.136 \\
\hline & & & & $(0.732)$ & $(0.331)$ \\
\hline \multirow[t]{2}{*}{ Goal Wine / Goal Spirits X $30^{\text {th }}$ tenure decile } & & & & 0.321 & 0.400 \\
\hline & & & & $(0.261)$ & $(0.359)$ \\
\hline \multirow[t]{2}{*}{ Goal Wine / Goal Spirits X $40^{\text {th }}$ tenure decile } & & & & $0.427 *$ & 0.434 \\
\hline & & & & $(0.246)$ & $(0.332)$ \\
\hline \multirow[t]{2}{*}{ Goal Wine / Goal Spirits X 50 th tenure decile } & & & & -0.040 & 0.009 \\
\hline & & & & $(0.242)$ & $(0.276)$ \\
\hline \multirow[t]{2}{*}{ Goal Wine / Goal Spirits X $60^{\text {th }}$ tenure decile } & & & & 0.116 & 0.167 \\
\hline & & & & $(0.248)$ & $(0.323)$ \\
\hline \multirow[t]{2}{*}{ Goal Wine / Goal Spirits X $70^{\text {th }}$ tenure decile } & & & & $0.640 * *$ & $0.642 * *$ \\
\hline & & & & $(0.269)$ & $(0.264)$ \\
\hline \multirow[t]{2}{*}{ Goal Wine / Goal Spirits X $80^{\text {th }}$ tenure decile } & & & & $0.910 * *$ & $0.841 * *$ \\
\hline & & & & $(0.418)$ & $(0.371)$ \\
\hline Goal Wine / Goal Spirits X 90 $0^{\text {th }}$ tenure decile & & & & (Omitted) & (Omitted) \\
\hline \multirow[t]{2}{*}{ Goal Wine / Goal Spirits X $100^{\text {th }}$ tenure decile } & & & & $0.593 * *$ & $0.654 * *$ \\
\hline & & & & $(0.247)$ & $(0.275)$ \\
\hline \multirow[t]{2}{*}{ Goal Wine / Goal Spirits X Salespersons origin in SSU } & & & & & 0.014 \\
\hline & & & & & $(0.191)$ \\
\hline \multirow[t]{2}{*}{$\begin{array}{l}\text { Goal Wine / Goal Spirits X High prior } \\
\text { year performance evaluation }\end{array}$} & & & & & 0.058 \\
\hline & & & & & $(0.095)$ \\
\hline
\end{tabular}




\begin{tabular}{|l|l|l|l|l|l|}
\hline Goal Wine / Goal Spirits X Experience with supervisor & & & & $0.025^{*}$ \\
\hline & & & & & $(0.014)$ \\
\hline & & & & & \\
\hline Constant & $1.083 * * *$ & $3.724 * * *$ & -1.042 & -0.811 & -0.518 \\
\hline & $(0.344)$ & $(1.111)$ & $(0.861)$ & $(0.697)$ & $(0.666)$ \\
\hline Period fixed effects? & YES & YES & YES & YES & YES \\
\hline Sales supervisor fixed effects? & NO & YES & YES & YES & YES \\
\hline Salespersons fixed effects? & NO & YES & YES & YES & YES \\
\hline Salespersons specific trend? & NO & NO & YES & YES & YES \\
\hline Tenure decile dummies? & NO & NO & NO & YES & YES \\
\hline Individual terms of the interactions included? & NO & NO & NO & YES & YES \\
\hline Observations & 1292 & 1292 & 1238 & 1238 & 1238 \\
\hline R-square & $14.11 \%$ & $26.42 \%$ & & & \\
\hline Standart Er &
\end{tabular}

Standard Errors (in Parentheses): Robust and Clustered at the salespersons level, $\ddagger 15 \%$ significance level, * $10 \%$ significance level, $* * 5 \%$ significance level, $* * * 1 \%$ significance level

Figure 1. Possible relationships between the ratio of goals and the ratio of sales.

Sales Product i Sales Product $\mathrm{j}$

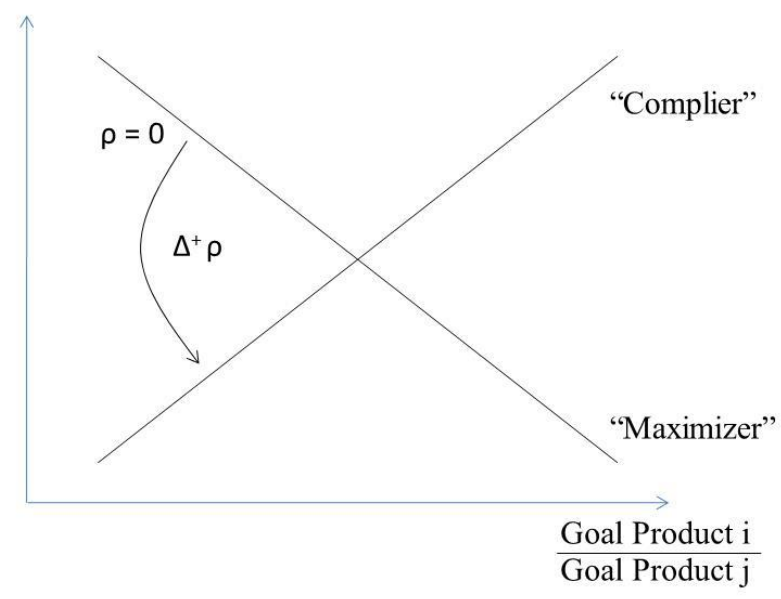


Figure 2. Distribution of the ratio Sales/Goal for periods prior to experiment.

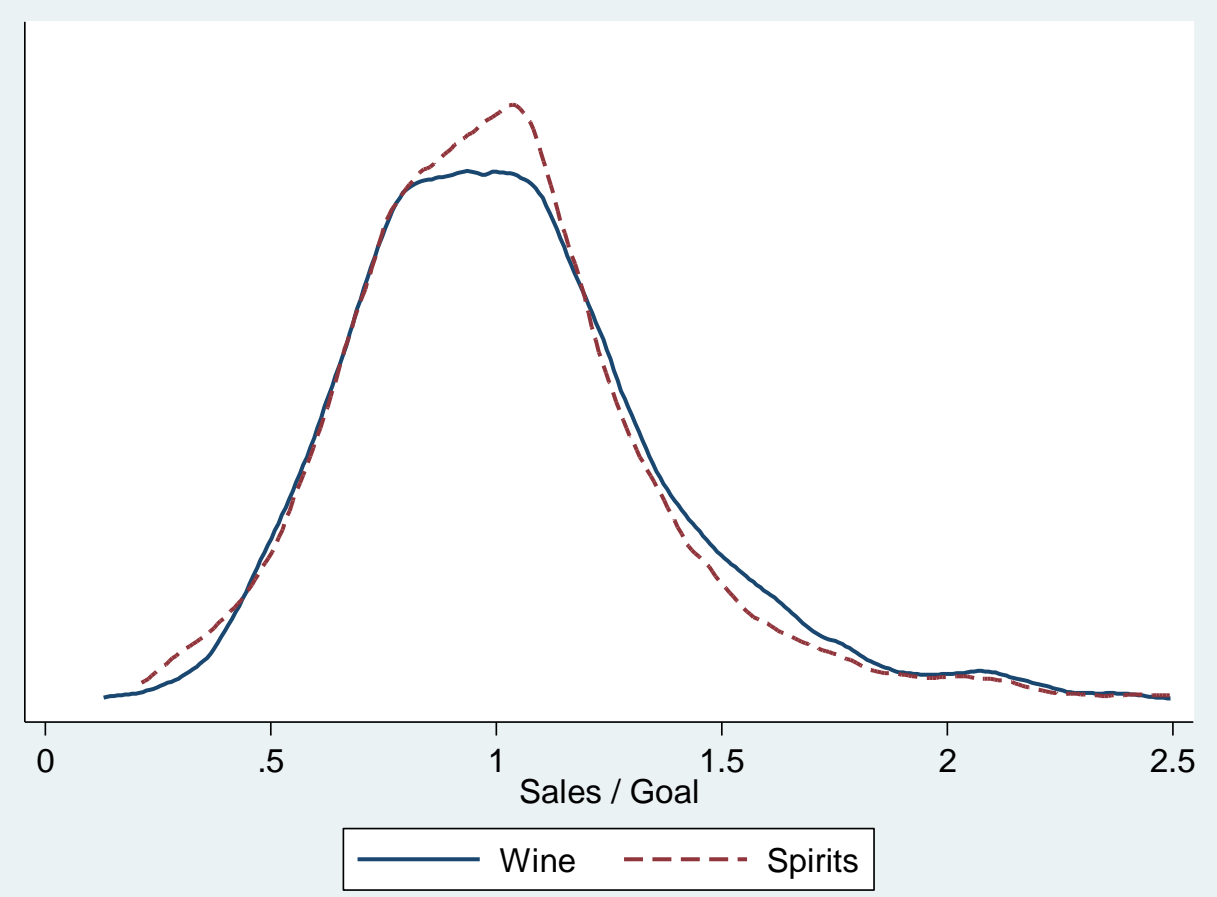

Figure 3. Tenure distribution of Salespersons, in months.

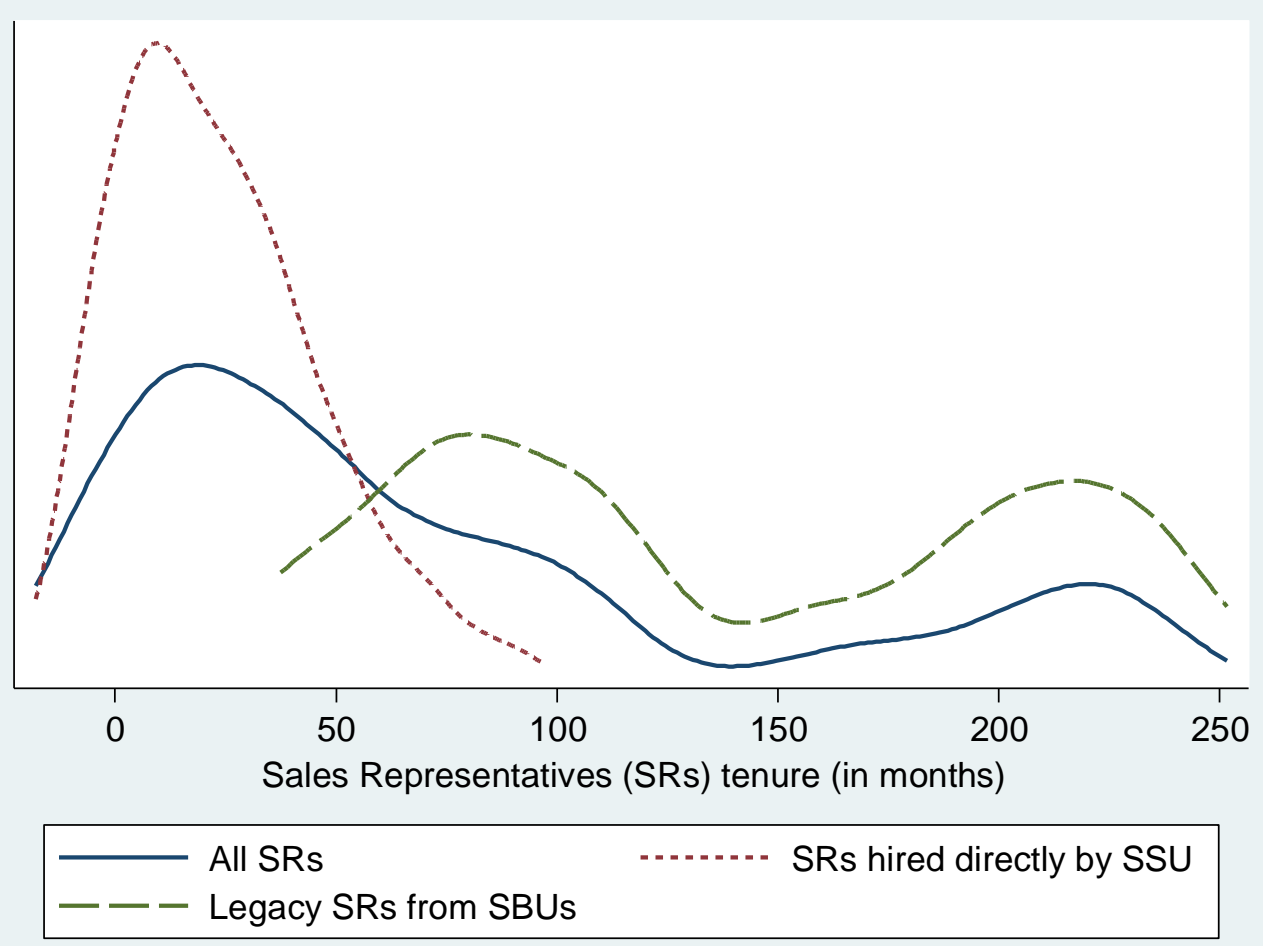


Figure 4. Ratchet effect of different supervisors. [Notes: We observe 14 sales supervisors (SPs), displayed on the horizontal axis. The SPs that have a $*$ are not present in the periods of the experiment. In parentheses we present the number of salespersons-month observations we have for each sales supervisor. The thin black line represents a 90\% confidence interval]

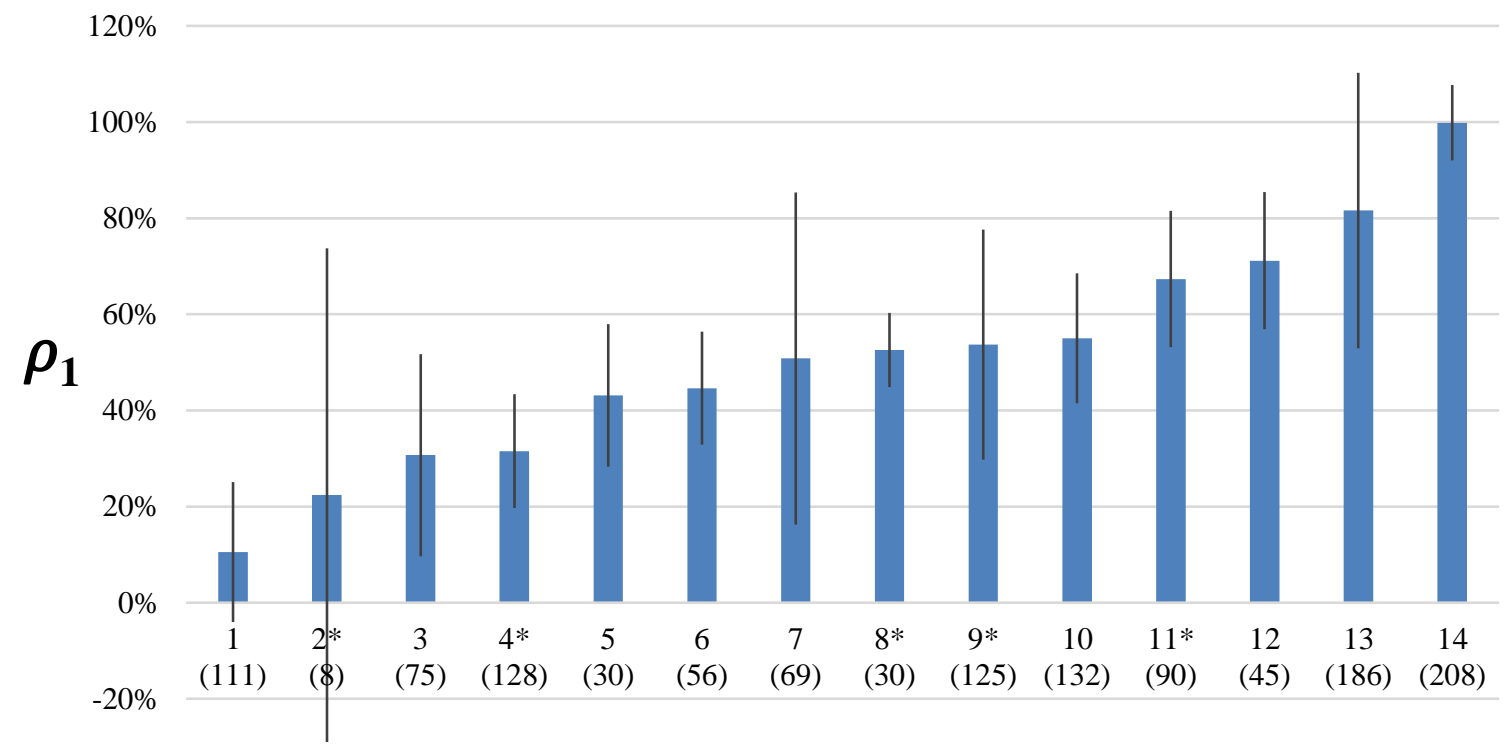

$-40 \%$

\section{Sales supervisor}

Figure 5. Using experimental data, the strategic effect emerges with ratcheting. [Note: This graph is built from the estimates of model 10 in table 3 . We computed the derivative of "sales wine / sales spirits" on "difference in treatment" and, while setting the covariates at their mean, we computed the value of expression varying the amount of ratcheting by supervisors. Then, we divided these values by $(1+15 \%) /(1-15 \%)-1$ and then we multiplied them by $+10 \%$ and $-10 \%]$

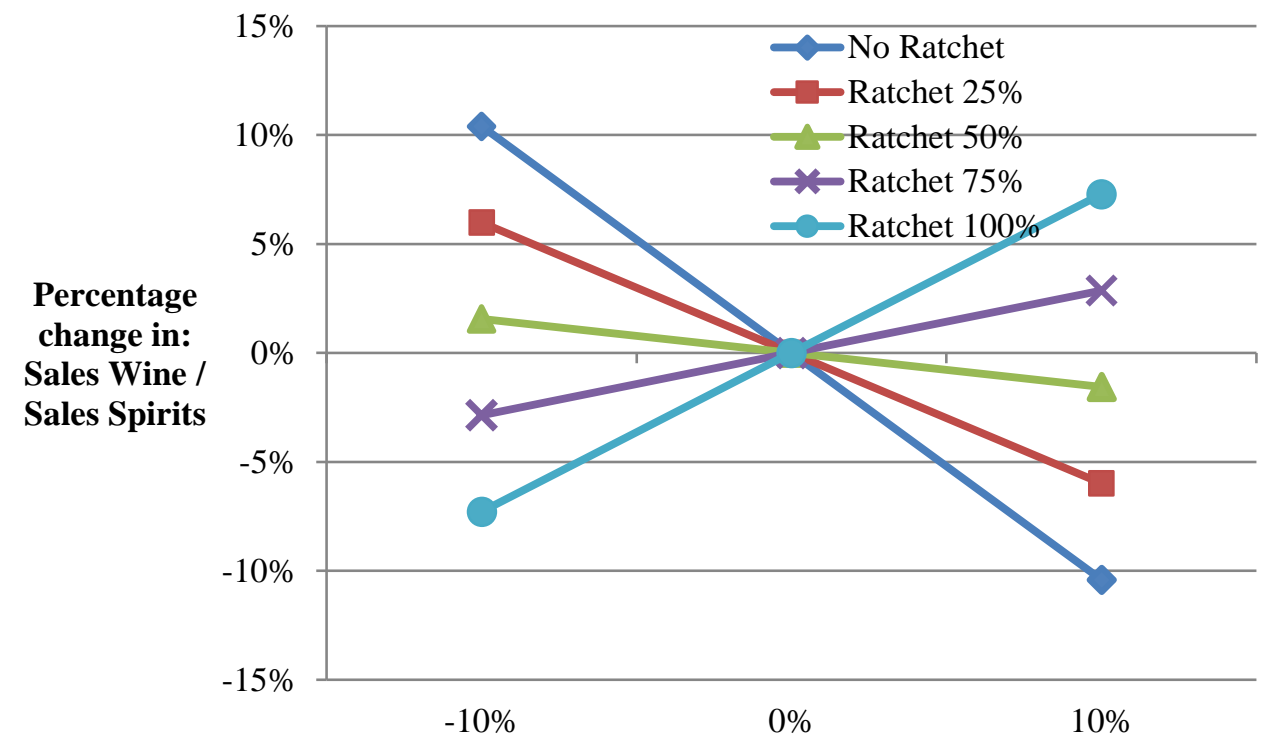

Percentage change in: Goal Wine / Goal Spirits 
Figure 6. Using experimental data, the direct effect varies according to tenure. [Note: This graph is built from the estimates of model 10 in table 3. We computed the derivative of "sales wine / sales spirits" on "difference in treatment" and, while setting ratchet equal to zero and the rest of covariates at their mean, we computed the value of expression when the $10^{\text {th }}$ decile dummy is both 1 and 0 , respectively. Then, we divided these two values by $(1+15 \%) /(1-15 \%)-1$ and then we multiplied them by $+10 \%$ and $-10 \%$ ]

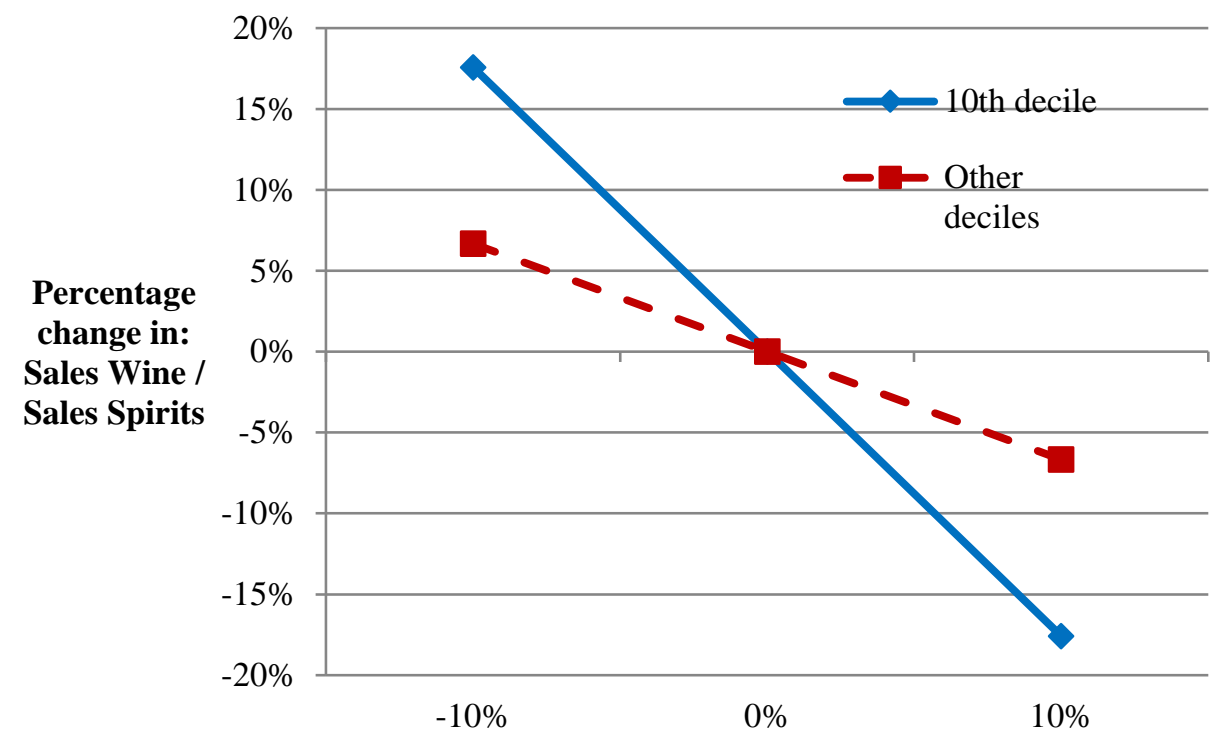

Percentage change in: Goal Wine / Goal Spirits

Figure 7. Using experimental data, the direct effect varies according to the origin of the salesperson. [Note: This graph is built from the estimates of model 10 in table 3 . We computed the derivative of "sales wine / sales spirits" on "difference in treatment" and, while setting ratchet equal to zero and the rest of the covariates at their mean, we computed the value of expression when the origin dummy is both 1 and 0 , respectively. Then, we divided these two values by $(1+15 \%) /(1-15 \%)-1$ and then we multiplied them by $+10 \%$ and $-10 \%]$

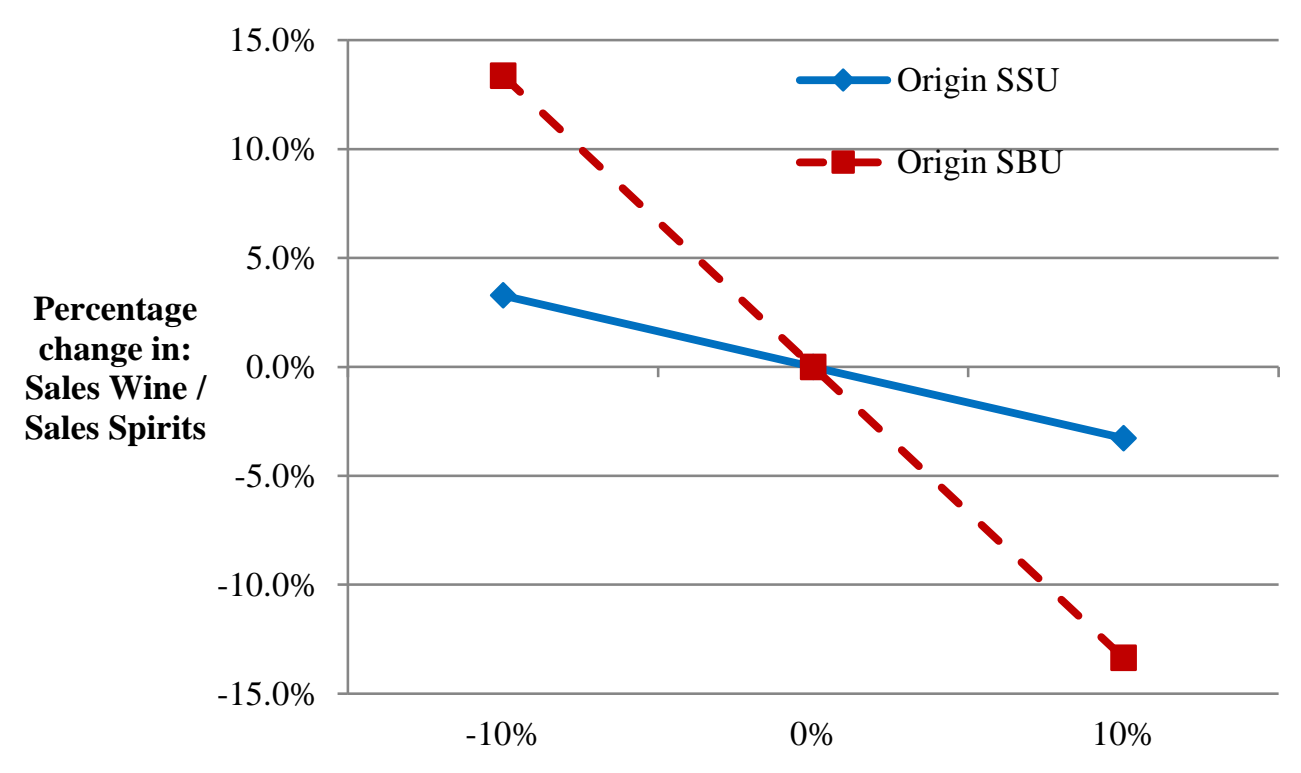

Percentage change in: Goal Wine / Goal Spirits 
Figure 8. Using historical data, $\beta_{1}$ varies according to tenure. [Note: This graph is built from the estimates of model 11 in table 6. We computed the derivative of "sales wine / sales spirits" on "goal wine / goal spirits" and, while keeping covariates at their mean, we computed the value of the expression activating each decile of tenure in turn. Then we graphed those values. The two dashed blue lines represent a $90 \%$ confidence interval]

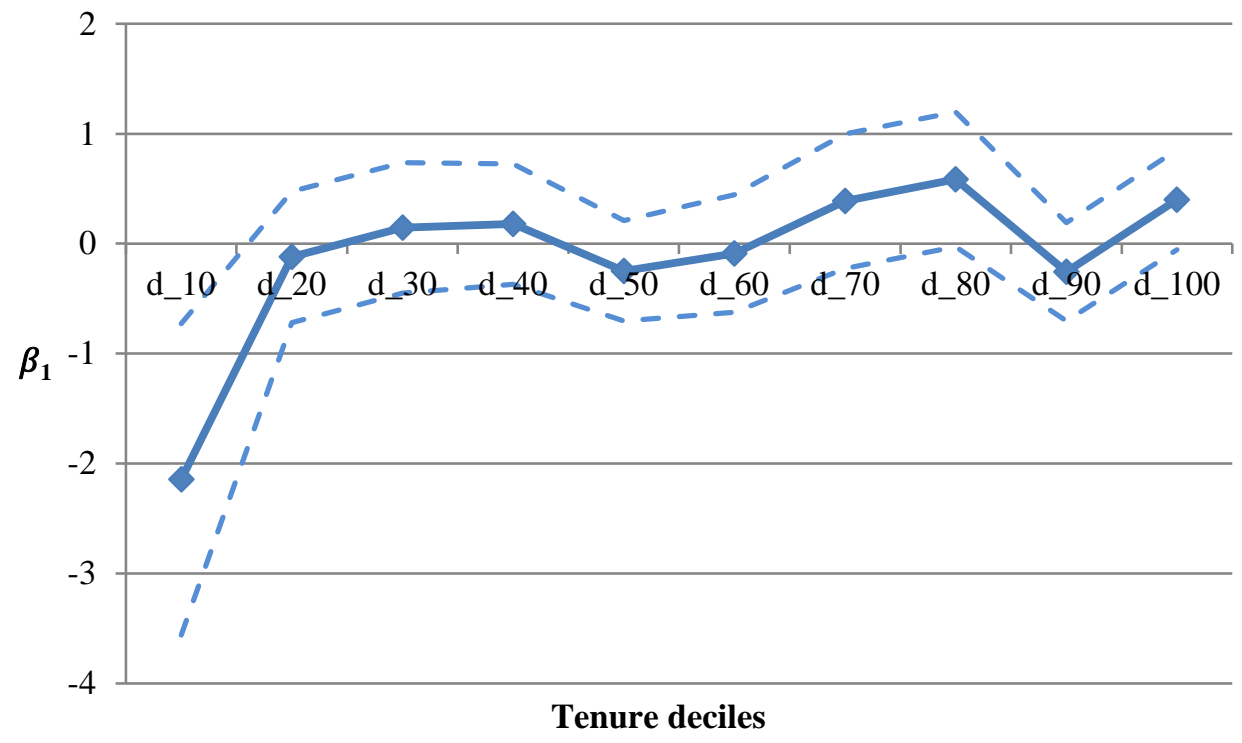

\section{Appendix: Formal analysis of prediction 2.}

To understand how the results in prediction 1 are affected by supervisor ratcheting behavior we compare the effects of an income compensated decrease in the current goal for product $\mathrm{ig}(\mathrm{i}, 1)$ and an increase in product $\mathrm{j} g(\mathrm{j}, 1)$; starting from an equilibrium situation in which agents find it optimal to fulfill goals; that is $\mathrm{g}^{0}(\mathrm{i}, 1)=\mathrm{s}^{0}(\mathrm{i}, 1)$ and $\mathrm{g}^{0}(\mathrm{j}, 1)=\mathrm{s}^{0}(\mathrm{j}, 1)$. In other words we study the effects of a change in goals starting from a situation in which $\mathrm{g}^{0}(\mathrm{i}, 1)$ and $\mathrm{g}^{0}(\mathrm{j}, 1)$ satisfy the first order conditions:

$$
\begin{aligned}
& U^{\prime}\left[f\left(\sum_{i=1}^{I}\left[\theta_{i} \times \frac{s(i, t)}{g(i, t)}\right]\right)\right] \times f^{\prime}\left(\sum_{i=1}^{I}\left[\theta_{i} \times \frac{s(i, t)}{g(i, t)}\right]\right) \times \frac{\theta_{i}}{g(i, t)}=\beta s(i, t) . \\
& U^{\prime}\left[f\left(\sum_{i=1}^{I}\left[\theta_{i} \times \frac{s(i, t)}{g(i, t)}\right]\right)\right] \times f^{\prime}\left(\sum_{i=1}^{I}\left[\theta_{i} \times \frac{s(i, t)}{g(i, t)}\right]\right) \times \frac{\theta_{j}}{g(j, t)}=\beta s(j, t) .
\end{aligned}
$$


Where goals are changed in such a way that total income $\sum_{i=1}^{I}\left[\theta_{i} \times \frac{s(i, t)}{g(i, t)}\right]$ is not affected by this change in goals. ${ }^{19}$

To simplify notation remember that we have assumed that the utility function is concave enough for the first order condition approach to be valid and therefore the function

$$
U^{\prime}\left[f\left(\sum_{i=1}^{I}\left[\theta_{i} \times \frac{s(i, t)}{g(i, t)}\right]\right)\right] \times f^{\prime}\left(\sum_{i=1}^{I}\left[\theta_{i} \times \frac{s(i, t)}{g(i, t)}\right]\right),
$$

is decreasing in $\sum_{i=1}^{I}\left[\theta_{i} \times \frac{s(i, t)}{g(i, t)}\right]$. This implies that the function is decreasing in $\mathrm{s}(\mathrm{i}, \mathrm{t})$ and $\mathrm{s}(\mathrm{j}, \mathrm{t})$ so we are simply going to write it as $\mathrm{w}[\mathrm{s}(\mathrm{i}, \mathrm{t}), \mathrm{s}(\mathrm{j}, \mathrm{t})]$, a decreasing function on both arguments.

Consider first the effect of decreasing $g(i, 1)$ from $g^{0}(i, 1)$ to $g^{1}(i, 1)$ and increasing $g(j, 1)$ in the absence of the ratchet effect. We know that the new chosen sales are $s^{*}(i, 1)$ and $s^{*}(j, 1)$ and that satisfy the first order conditions

$$
\mathrm{w}\left[s^{*}(\mathrm{i}, 1), s^{*}(\mathrm{j}, 1)\right] \times \frac{\theta_{i}}{g^{1}(\mathrm{i}, 1)}=\beta s^{*}(i, 1) .
$$

and

$$
\mathrm{w}\left[s^{*}(\mathrm{i}, 1), s^{*}(\mathrm{j}, 1)\right] \times \frac{\theta_{i}}{g^{1}(\mathrm{j}, 1)}=\beta s^{*}(j, 1)
$$

And as we showed in our prediction 1 the ratio $s(\mathrm{i}, \mathrm{t}) / \mathrm{s}(\mathrm{j}, \mathrm{t})$ must have increased. Because we have made the change compensated to keep income constant, the function w[] does not change, which implies s(i,1) must have increased and $\mathrm{s}(\mathrm{j}, 1)$ must have decreased.

Suppose now that the agent is subject to ratchet effect. In particular, this implies that as the agent increase sales beyond $\mathrm{g}^{1}(\mathrm{i}, \mathrm{t})$ the goal of the next period increased by $\rho$. Including ratcheting, and using the envelop theorem for the utility on the second period, the derivative of the agent's utility with respect to sales for products $\mathrm{i}$ and $\mathrm{j}$ are now given by

\footnotetext{
${ }^{19}$ This is the situation that best reflect the exogenous changes in goals that we introduce during our experiment where we increased and decrease goals of the two smaller items by $15 \%$ to try to avoid affecting the agent's income.
} 


$$
\mathrm{w}[\mathrm{s}(\mathrm{i}, 1), \mathrm{s}(\mathrm{j}, 1)] \times \frac{\theta_{i}}{g(i, t)}-\rho \delta U^{\prime}\left[f\left(\sum_{i=1}^{I}\left[\theta_{i} \times \frac{s(i, 2)}{g(i, 2)}\right]\right)\right] \times f^{\prime}\left(\sum_{i=1}^{I}\left[\theta_{i} \times \frac{s(i, 2)}{g(i, 2)}\right]\right) \times \frac{\theta_{i}}{g(i, 2) g(i, 2)}-
$$

$\beta s(i, 1)$

and

$$
\mathrm{w}[\mathrm{s}(\mathrm{i}, 1), \mathrm{s}(\mathrm{j}, 1)] \times \frac{\theta_{i}}{g(i, 1)}-\beta s^{*}(j, 1) .
$$

The derivative for product $i$ has change because now increasing sales for product $i$ increase the goal of the product tomorrow by a factor $\rho$. This extra term only exists if sales for product i exceeds the new goal $\mathrm{g}^{1}(\mathrm{i}, 1)$. Otherwise the derivative is the same as it was without ratchet effect. (The case when sales for product i decrease will be analyzed at the end)

First notice that evaluated at $s^{*}(i, 1)$ and $s^{*}(j, 1)$, (the optimal sales without ratchet effect) the first order conditions will not be met. In particular the derivative with respect to $s(i, t)$ is negative. Intuitively now there is an extra negative effect of increasing sales for category 1 . As a result the agent is better decreasing sales for product i (compared to the case without ratcheting).

Second notice that because the sales for product $i$ decreases, the first order condition for product $j$ will also fail to hold at level $\mathrm{s}^{*}(\mathrm{j}, 1)$. Remember that w[.] is a decreasing function, so to satisfy the first order condition now the sales for product $\mathrm{j}$ will have to increase relative to the level $\left.\mathrm{s}^{*}(\mathrm{j}, 1)\right)$.

These two effects move the ratio $s(i, 1) / s(j, 1)$ down (compared to the case without ratchet), which makes the change in ratio of sales less sensitive to a change in goals. We have shown that provided there exists a new equilibrium where sales for product $\mathrm{i}$ increases, then ratchet effect makes the ratio of sales less sensitive to changes in goals.

Now we argue that if the agent cares sufficiently about the future and the ratchet effect as measured by the parameter $\rho$ is sufficiently strong it is possible that an equilibrium where sales for product i s(i,1) increases may not exist. Take again the derivative with respect to product $\mathrm{i}\left(\operatorname{assuming} \mathrm{s}(\mathrm{i}, 1)>\mathrm{g}^{1}(\mathrm{i}, 1)\right.$ ).

$$
\mathrm{w}[\mathrm{s}(\mathrm{i}, 1), \mathrm{s}(\mathrm{j}, \mathrm{t})] \times \frac{\theta_{i}}{g(i, t)}-\rho \delta U^{\prime}\left[f\left(\sum_{i=1}^{I}\left[\theta_{i} \times \frac{s(i, 2)}{g(i, 2)}\right]\right)\right] \times f^{\prime}\left(\sum_{i=1}^{I}\left[\theta_{i} \times \frac{s(i, 2)}{g(i, 2)}\right]\right) \times \frac{\theta_{i}}{g(i, 2) g(i, 2)}-\beta s(i, t)
$$


Observe that if $\rho$ and $\delta$ are sufficiently large, this might be negative for every $s(i, 1)>g^{1}(i, 1)$. In such a case the optimal sales level is given by $\mathrm{s}(\mathrm{i}, 1)=\mathrm{g}^{1}(\mathrm{i}, 1)$. To see why, observe that clearly the agent is not better of increasing sales because, if she increase sales the derivative is given by the equation above which is negative and so her utility goes down. Also the agent will not want to decrease beyond this point, as if she decreases beyond this point, ratchet effect does not take place and the derivative is given by

$$
\mathrm{w}[\mathrm{s}(\mathrm{i}, 1), \mathrm{s}(\mathrm{j}, \mathrm{t})] \times \frac{\theta_{i}}{g(i, t)}-\beta s(i, t)
$$

The first order condition holds with equality at $\mathrm{s}^{*}(\mathrm{i}, \mathrm{t})>\mathrm{g}^{1}(\mathrm{i}, 1)$; so evaluated as $\mathrm{s}(\mathrm{i}, 1)=\mathrm{g}^{1}(\mathrm{i}, 1)$ the derivative is positive. As a result, if the agent decrease sales beyond this point, her utility decreases.

Finally notice that because the function $w[]$ is decreasing, this decrease in $s(i, 1)$ from $g^{0}(i, 1)$ to $g^{1}(i, 1)$ will induce the agent to increase sales of product $\mathrm{j}$. Observe that this implies that as we reduce the ratio of sales $\mathrm{g}(\mathrm{i}, \mathrm{t}) / \mathrm{g}(\mathrm{j}, \mathrm{t})$ the ratio of sales is also reduced. As a result if parameters $\delta$ and $\rho$ are sufficiently large it is possible that the ratio of sales depends positively on changes to the ratio of goals. This is the second prediction of our paper.

The predictions made in the model can easily be seen by a numerical example. To perform the numerical example we assume that the utility function is logarithmic, that goals were originally set at $g(i, t)=g(j, t)=1$; that parameter $\theta$ was also equal to 1 and $\beta=0,5$. It is straightforward to see the first order conditions are met at $s(\mathrm{i}, 1)=\mathrm{s}(\mathrm{j}, 1)=1$.

Then we look at the effect on the ratio of sales of increasing the goal of product $j$ and decreasing the goal of product $\mathrm{i}$ in $10 \%$ respectively for different levels of expected ratchet (parameter $\rho$ ). The results are shown in the table below. As predicted in the analysis presented above, the negative relationship between goals and sales become weaker for larger levels of $\rho$, and for sufficiently high levels the relationship becomes positive.

\begin{tabular}{|c|c|}
\hline Ratchet $(\rho)$ & Change in sales ratio \\
\hline 0 & $-18.19 \%$ \\
\hline 0.16 & $-14.38 \%$ \\
\hline
\end{tabular}




\begin{tabular}{|c|c|}
\hline 0.4 & $-9.36 \%$ \\
\hline 0.64 & $-1.77 \%$ \\
\hline 0.8 & $3.55 \%$ \\
\hline 0.96 & $7.5 \%$ \\
\hline
\end{tabular}

